\title{
Effect of freshwater from the West Greenland Current on the winter deep convection in the Labrador Sea
}

\author{
T. Kawasaki ${ }^{\mathrm{a}, \mathrm{b}, *}$, H. Hasumi ${ }^{\mathrm{b}}$ \\ ${ }^{a}$ National Institute of Polar Research, 10-3, Midoricho, Tachikawa, Tokyo, 190-8518, \\ Japan \\ ${ }^{b}$ Atmosphere and Ocean Research Institute, the University of Tokyo, 5-1-5, \\ Kashiwanoha, Kashiwa-shi, Chiba, 277-8568, Japan
}

\begin{abstract}
The effect of mesoscale eddies on the deep convection in the Labrador Sea is examined by using a realistically configured eddy-resolving ice-ocean model. The near-surface boundary current flowing into the Labrador Sea is realistically simulated, namely the West Greenland Current which carries upper/onshore fresh and lower/offshore warm water, and eddies separating from these boundary currents with cold/fresh water atop warm/salty water are also well reproduced. The modeled convection is confined to the southwestern Labrador Sea as observed, and its depth and width are reproduced better than in previous modeling studies. Although previous modeling studies demonstrated only the importance of eddy-induced heat transport in inhibition of deep convection over the central to northern Labrador Sea, our study found that the eddy-induced transport of near-surface fresh water also significantly contributes.
\end{abstract}

Keywords: freshwater transport, Labrador Sea, winter deep convection,

\footnotetext{
*Corresponding author, Tel.: +81-4-7136-4417; Fax: +81-4-7136-4375

Email address: kawasaki@aori.u-tokyo.ac.jp (T. Kawasaki)
} 
mesoscale eddy, ocean general circulation model

\section{1. Introduction}

2 The Labrador Sea is one of the most prominent regions in the World 3 Ocean where open ocean convection takes place (e.g., Clarke and Gascard, 4 1983; Marshall and Schott, 1999). The open ocean convection reaches 1000$52300 \mathrm{~m}$ depth (Lazier et al., 2002) and forms Labrador Sea Water (LSW).

6 Many studies have suggested that the LSW influences the global climate, as 7 it is one of the source waters for the North Atlantic Deep Water (NADW) and 8 thus affects the Atlantic meridional overturning circulation (Weaver et al., 9 1999; Bryden and Imawaki, 2001). The winter-time deep convection is pre-

conditioned by weak stratification in the Labrador Sea interior associated with the cyclonic circulation which accompanies a system of strong boundary currents made up of the Labrador Current (LC) and the West Greenland Current (WGC). The smaller scale $(\sim 100-200 \mathrm{~km})$ localized cyclonic circulation, which exposes water to wintertime heat loss for a longer period of time, also preconditions the deep convection in the western Labrador Sea (Lavender et al., 2002).

The large-scale cyclonic boundary current system (WGC and LC) transports buoyancy into the Labrador Sea (Cuny et al., 2002). The Irminger Water (IW), which originates in the Irminger Sea, is relatively warm and salty and transported by WGC and LC in the subsurface along the continental slope. On the other hand, cold/fresh water, which is originated in the Greenland and Arctic Seas, is transported by WGC along the vicinity of the Greenland coast in the surface layer. We use the "IW" instead of "Irminger 
Current", which has been used in many previous studies, since there is dynamically one current (WGC) transporting two water masses (Fratantoni and Pickart, 2007). This layered structure is also seen in the central Labrador Sea and formed by the eddy-induced lateral transport from the shelf region (Lilly et al., 1999). High activity of mesoscale eddies is observed by surface drifters (Cuny et al., 2002), floats and satellites (Prater, 2002), and moorings (Lilly et al., 2003) in the Labrador Sea. Several observational studies have suggested the important role of such mesoscale eddies in the inhibition of winter deep convection and restratification of vertically homogenized water columns in the Labrador Sea interior by transporting buoyancy from the WGC (Lilly et al., 1999; Prater, 2002). Pickart et al. (2002) suggested that the eddy flux of buoyant water confines deep convection to the southwestern Labrador Sea. Coarse resolution models tend to simulate too wide or too deep convection in the Labrador Sea possibly because of the lack of such eddy-induced buoyancy transport (e.g., England, 1993; Komuro and Hasumi, 2005).

Chanut et al. (2008) classified the eddies into convective eddies (CEs), boundary current eddies (BCEs), and Irminger Rings (IRs). The CEs are generated by baroclinic instability of the rim current encompassing the convection area and more rapidly (less than two months) restratify the homogenized water columns than air-sea flux ( half year) does in the shallow layer (Jones and Marshall, 1997).

The size of CEs is of the order of the Rossby deformation radius for the first baroclinic mode $(\sim 10 \mathrm{~km})$. The BCEs have a comparable size to CEs and are formed by baroclinic instability of the boundary currents (WGC and LC) throughout a year. The IRs are generated by instability 
of the WGC at the Cape Desolation (Katsman et al., 2004). There has not been an established agreement among several studies on whether the IRs are generated by barotropic, baroclinic, or mixed instability (Eden and Boning, 2002; Bracco and Pedlosky, 2003). The IRs are larger (diameter is $\sim 40-50 \mathrm{~km}$ ) and more long-lived (several months to one year) than the BCEs and CEs (living time is less than one month). While the source of the IRs, which is detected by the maximum of sea surface height variability (Lilly et al., 2003), is confined to the northeastern Labrador Sea, their long lifetimes cause the significant buoyancy transport from the boundary current region to the Labrador Sea interior. The IRs contain cold/fresh water in the upper part and warm/saline core at depth and transport these properties to the Labrador Sea interior (Lilly and Rhines, 2002; Lilly et al., 2003; Hatun et al., 2007). Chanut et al. (2008) suggested that the buoyancy transported by the BCEs is also significant in the Labrador Sea, since the number of the BCEs is much larger than that of the IRs. On the other hand, Gelderloos et al. (2011) claimed that the BCEs are not essential for buoyancy transport toward the interior Labrador Sea.

High resolution modeling is necessary to examine the effect of eddies on the deep convection in the Labrador Sea, and such modeling became feasible only recently. Tréguier et al. (2005) reported the inter-comparison of four high-resolution models in the North Atlantic subpolar gyre (horizontal resolution is $1 / 6$ to $1 / 12^{\circ}$ ). They pointed out that the pattern of deep convection in the Labrador Sea depends on the transport of freshwater and heat by the boundary current (e.g., WGC and LC). The deep convection unrealistically developed (depth of convection is $\sim 3000-3500 \mathrm{~m}$ ) in three models. Although 
the depth of convection is about $1300 \mathrm{~m}$ in the remaining model, the location of convection is the eastern Labrador Sea, which is unrealistic. They argued that salinity drifts away from the observed state because of salinization of the boundary current.

Chanut et al. (2008) investigated the effect of eddies on the open ocean convection and restratification in the Labrador Sea by using an eddy-resolving (horizontal resolution is $1 / 15^{\circ}$ ) ocean model. The water column homogenized by deep convection is restratified by the CEs in shallow layer during the early phase, and the BCEs and IRs transport the warm water from the WGC region to the Labrador Sea interior and restratify the water columns at depth during the later season in their model. These roles of eddies had previously been suggested by many studies (e.g., Jones and Marshall, 1997; Prater, 2002; Lilly et al., 2003). However, Chanut et al. (2008) demonstrated only the effect of the heat from the IW, since they failed to represent the cold/low-salinity surface water in the WGC perhaps due to coarse horizontal resolution in the data used for surface restoring of salinity. The observed trajectory of eddies originating from the WGC shows that these eddies move to the interior Labrador Sea with cold/fresh water in the upper layer (e.g., Pickart et al., 2002; Lilly et al., 2003), and their importance in inhibition of deep convection and restratification of vertically homogenized water columns has also been pointed out (Schmidt and Send, 2007).

McGeehan and Maslowski (2011) quantitatively assessed the shelf-basin freshwater transport in the western Labrador Sea by using an eddy-resolving model (horizontal resolution is $\sim 9 \mathrm{~km}$ ). Unfortunately, the deepest convection takes place in the northeastern Labrador Sea in their model. They 
discussed that the discrepancy from the observed feature of deep convection is due to the absence of the IRs having low salinity water on their top. They argued that the lack of the surface low salinity is caused by the error in the surface salinity distribution used for nudging, shortage of runoff from Greenland, and insufficient resolution to reproduce the narrow coastal current along the Greenland coast in their model.

Thus, the importance of the eddy-induced freshwater transport for the restratification in the region of open ocean deep convection in the Labrador Sea has not been fully clarified from a quantitative point of view. We quantitatively investigate the roles of the eddies in the deep convection in the Labrador Sea through their buoyancy (heat and freshwater) transport by using an eddy-resolving ocean general circulation model.

The numerical model and experimental design are described in the next section. The results of experiments are shown in section 3. Section 4 presents the discussion and conclusion.

\section{Model description and experimental design}

The ice-ocean general circulation model employed in this study is COCO version 4 (Hasumi, 2006). The model incorporates a second-order moments conserving scheme for tracer advection (Prather, 1986). The turbulence closure scheme of Noh and Kim (1999) is applied for diagnosing vertical viscosity and diffusivity. Background vertical viscosity and diffusivity are $1.0 \times 10^{-4}$ and $2.0 \times 10^{-5} \mathrm{~m}^{2} \mathrm{~s}^{-1}$, respectively. The horizontal bi-harmonic friction with Smagorinsky-like viscosity is utilized, where the value of controlling parameter is set to 3 (Griffies and Hallberg, 2000). 
The model domain is global. The model is formulated on the general curvilinear horizontal coordinates. Its poles are placed on the Labrador Peninsula and Greenland, and the horizontal resolution is eddy resolving (4-5 km) in the Labrador Sea, eddy permitting around the Cape Hatteras, Irminger and Greenland Seas (10-50 km), and coarse (> $50 \mathrm{~km})$ in other regions (Figure 1a, b). The bathymetry is constructed from a 2-min topography dataset (ETOPO2, National Geophysical Data Center, National Oceanic and Atmospheric Administration). There are 45 vertical levels. The layer thickness varies from $5 \mathrm{~m}$ (top) to $500 \mathrm{~m}$ (bottom).

The model is initiated by climatological temperature and salinity (World Ocean Atlas 2009, Locarnini et al., 2010; Antonov et al., 2010) with no flow and sea ice. Temperature and salinity are restored to observed monthly climatology (World Ocean Atlas 2009, Locarnini et al., 2010; Antonov et al., 2010) with a damping time scale of 30 days at all depths over the whole domain during the first six months (January to June of the first year) to reproduce the mean circulation in the Labrador Sea. The sea surface heat, freshwater, and momentum fluxes are calculated using a daily climatology of surface air properties based on the ECMWF reanalysis (OMIP-forcing version 3; Roske, 2005). Restoring of sea surface salinity is not employed, since it may cause failure in reproducing the low salinity water in the WGC as in previous studies (Rattan et al., 2010; McGeehan and Maslowski, 2011). To avoid the drift of model, we employ nudging of temperature and salinity to monthly climatology in the northeastern Atlantic Ocean (shown as a box in Figure 1b), which is the source of warm/saline water of the WGC. Note that if we apply temperature and salinity nudging around the Denmark Strait 
for the cold/fresh water from the Greenland Sea and the Arctic Ocean, the low salinity water (the narrow East Greenland Current) is not reproduced because of coarseness of climatology data as pointed out by Rattan et al. (2010).

The 20-year time series of temperature, salinity and mean kinetic energy averaged in the Labrador Sea show that the state of ocean is in a quasi-steady state except for the first few years (Figure 2). This means that the boundary conditions and modeled physics in the Labrador Sea are balanced with the climatological initial state. So, it is meaningful to analyze the modeling results for this period. On the other hand, when we run the model without nudging of temperature/salinity, the modeled state continuously drifts away from the initial state afterwards (dashed lines in Figure 2). This drift is caused by biases in temperature and salinity in the upstream region (i.e., the North Atlantic Ocean) of the boundary current which comes into the Labrador Sea, because the resolution is coarse and restoring for sea surface salinity is not applied there. Although we succeeded in avoiding such a drastic drift for basin-averaged kinetic energy, temperature, and salinity (Figure 2), there still are drifts in localized features. For instance, gradual deepening of winter convection in the interior Labrador Sea is induced after the sixth year in our model. As discussed later, the eddy activity is still underestimated due perhaps to insufficient resolution or lack of a proper parameterization, and this causes the drift of deep convection. It is difficult to improve the model further and remove this drift without nudging of sea surface salinity. For the purpose of this study, therefore, it is desirable to analyze an early period when the oceanic state is more realistic than in the later period. Thus, 
the results presented hereafter are taken from the sixth and tenth years of model integration.

To investigate the role of eddies, another case is conducted where mesoscale eddies are artificially suppressed. As it is known that the IRs are generated through instability of the WGC due to the sharp continental slope off the Cape Desolation (Katsman et al., 2004; Bracco et al., 2008), a more gentle continental slope is applied off the Cape Desolation in this case by smoothing the bathymetry. This is hereafter referred to as the SMOOTH case (Figure $1 \mathrm{~d}$ and e). Such bathymetry smoothing is also applied by a previous study (Chanut et al., 2008). When the name of the case is not described explicitly, the presented result is for the control case.

\section{Results}

\subsection{Mean state}

The cyclonic circulation including the WGC and LC, which are part of the North Atlantic subpolar gyre, is qualitatively well reproduced in the Labrador Sea (Figure 3a). The 5-year mean volume transports of the WGC and LC are about 25 and $30 \mathrm{~Sv}$, respectively, which are calculated by the local minima of the barotropic stream function. The simulated mean WGC speed is $35-40 \mathrm{~cm} \mathrm{~s}^{-1}$ in the shallow layer, which is consistent with an estimate from drifter data (35 $\mathrm{cm} \mathrm{s}^{-1}$; Cuny et al., 2002). The Labrador Current speed around the Hamilton Bank is $25-35 \mathrm{~cm} \mathrm{~s}^{-1}$ and in agreement with the observed values of $20 \mathrm{~cm} \mathrm{~s}^{-1}$ to the north and $30 \mathrm{~cm} \mathrm{~s}^{-1}$ to the south of the Hamilton Bank (Cuny et al., 2002). The weak counter currents adjacent to the cyclonic boundary currents, which has been observed by Lavender et al. 
(a)

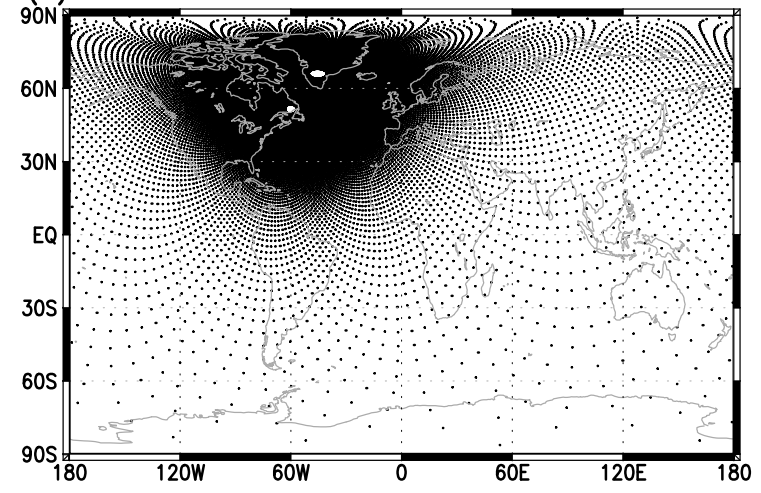

(c)

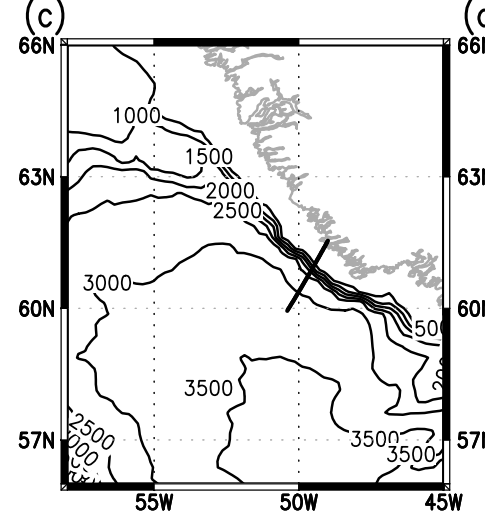

(b)

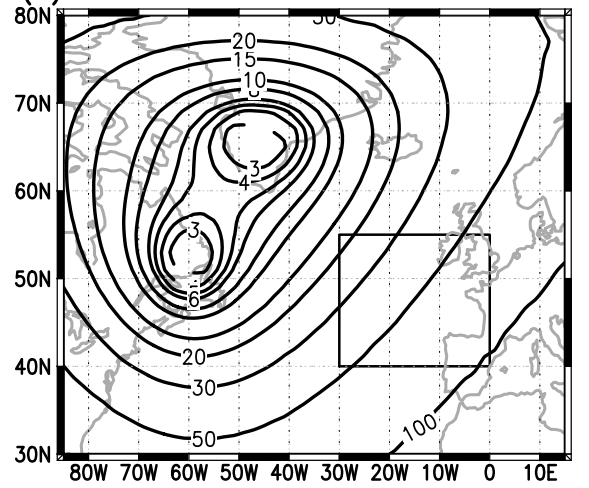

(e)

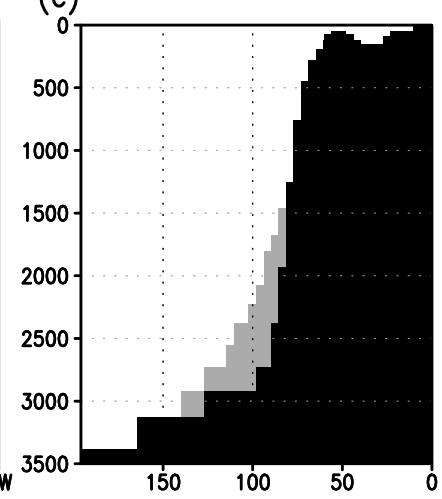

Figure 1: (a) Geographical location of the grid points of the model. (b) The horizontal resolution of the model around the Labrador Sea $(\mathrm{km})$. The rectangle indicates the domain of temperature and salinity nudging to climatology. The ocean depth around the northeastern Labrador Sea in (c) the control case and (d) the SMOOTH case. The contour interval is $500 \mathrm{~m}$. (e) The cross section of the model bathymetry at right angle to the coast for control case (black) and SMOOTH case (gray). The location of this section is shown as a solid line in (c) and (d). The $\mathrm{x}$ and $\mathrm{y}$ labels indicate the distance from the coast of Greenland $(\mathrm{km})$ and depth $(\mathrm{m})$, respectively 

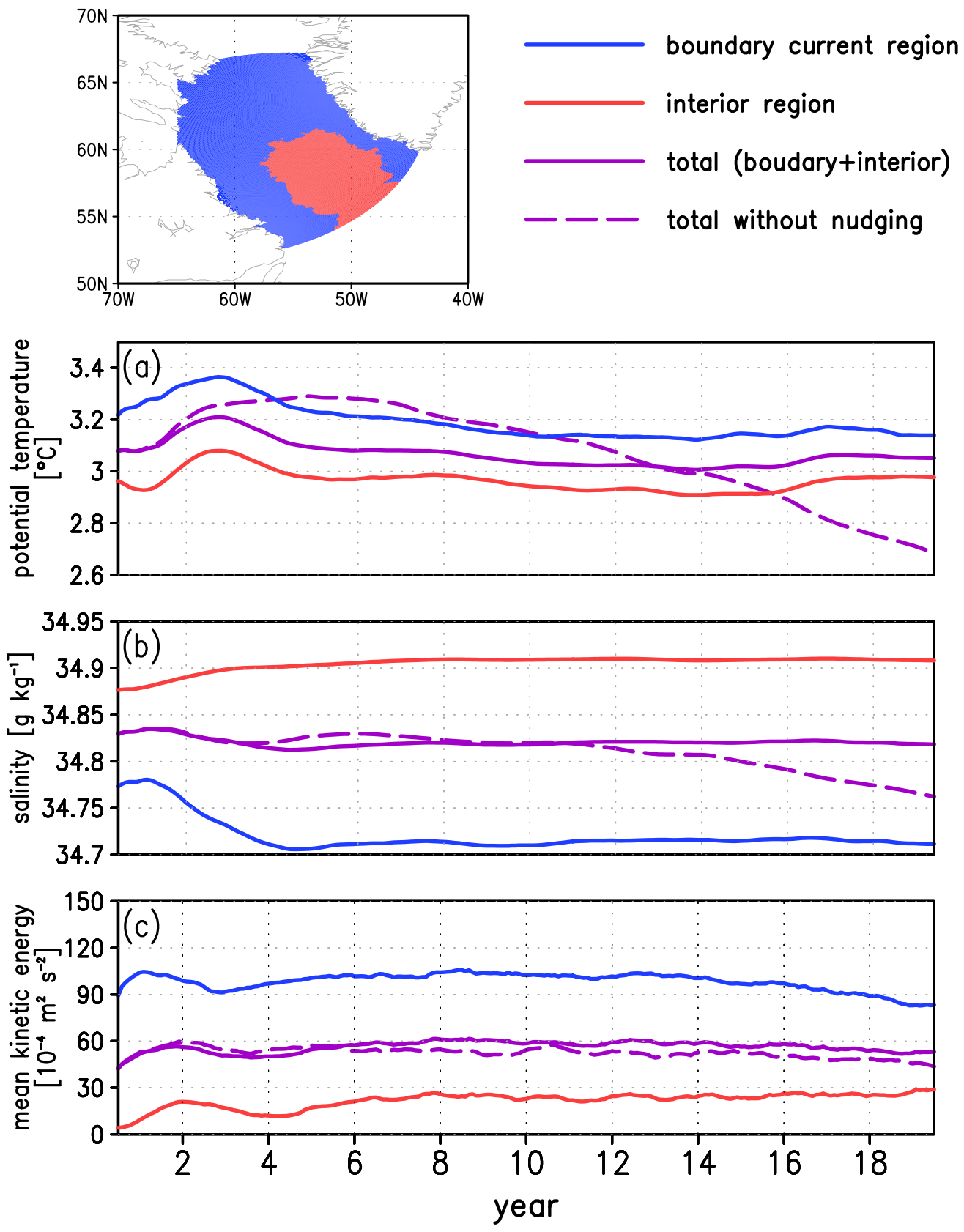

Figure 2: 1-year running means of (a) potential temperature $\left({ }^{\circ} \mathrm{C}\right),(\mathrm{b})$ salinity $\left(\mathrm{g} \mathrm{kg}^{-1}\right)$, and (c) mean kinetic energy $\left(10^{-4} \mathrm{~m}^{2} \mathrm{~s}^{-2}\right)$ averaged in the Labrador Sea for the integration period. The blue, red, and purple lines indicate the average in the boundary current region, the interior, and both of them, respectivel 1,1 as shown in the upper panel. The dashed purple line indicates the average in whole of the Labrador Sea (boundary + interior regions) without temperature/salinity nudging in the upstream of the WGC (which is shown as a box in Figure $1 \mathrm{~b})$. 


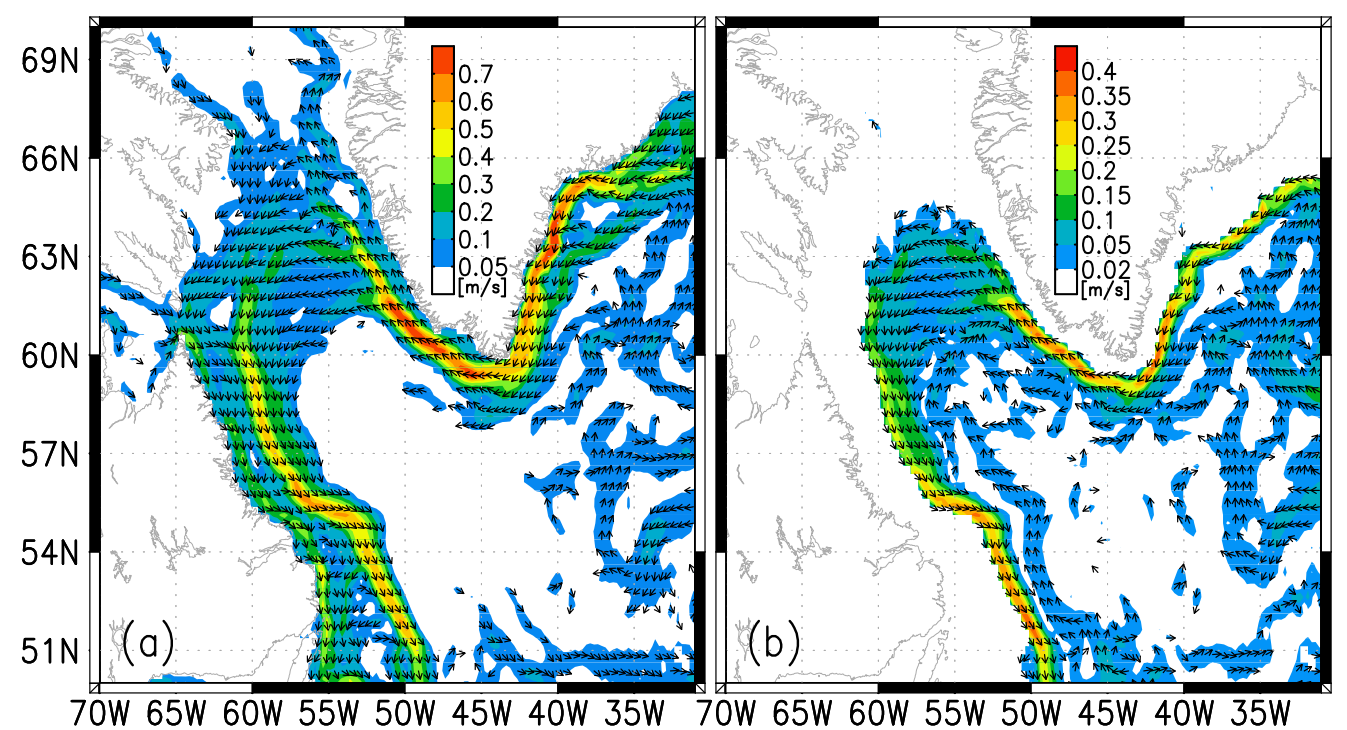

Figure 3: 5-year mean horizontal velocity at (a) the sea surface and (b) $715 \mathrm{~m}$ depth. The color shade and vector indicate the scalar and direction of velocity, respectively. The vectors are plotted at every 0.5 degree in longitude and latitude.

(2000) and Fischer et al. (2010) and preconditions the deep convection in western Labrador Sea (Lavender et al., 2002) and enhances the export of LSW to the Irminger Sea (Myers and Deacu, 2004), are also reproduced at intermediate depths (Figure 3b).

Potential density, potential temperature, and salinity along the AR7W line in March (winter) and June (summer) in our model are shown in Figure 4. Many observations have been conducted along the AR7W line, which is a hydrographic section across the Labrador Sea connecting Misery Point (Labrador Peninsula) and Cape Desolation (Greenland). The low density water along the both boundaries is transported from the Irminger and Greenland Seas by the cyclonic boundary currents (Figures 4). The low density 
water is composed of the subsurface warm/salty water along the continental slope (IW) and the near-surface (above $150 \mathrm{~m}$ depth) cold/fresh water on the shelf in the WGC. These features of the WGC are consistent with observations (Figure 5). The maximum of temperature and salinity of the IW along the AR7W in May are $5.5{ }^{\circ} \mathrm{C}$ and $35.01 \mathrm{~g} \mathrm{~kg}^{-1}$, respectively, which are slightly warmer and saltier, but similar to the observed values of Cuny et al. (2002) $\left(4.2-5.4{ }^{\circ} \mathrm{C} / 34.88-34.99 \mathrm{~g} \mathrm{~kg}^{-1}\right)$. The temperature and salinity of cold/fresh water near the surface is $-1.0-0.0{ }^{\circ} \mathrm{C}$ and $31.5-33.0 \mathrm{~g} \mathrm{~kg}^{-1}$, respectively, and these values are in the range of a high quality climatological data-set (Kulan and Myers, 2009).

Sea surface cooling vertically homogenizes density (potential temperature and salinity) on the Labrador side of the Labrador Sea interior in winter (Figures $4 \mathrm{~b}, \mathrm{~d}$ ). The location and width of the homogenized water column along AR7W are consistent with the observation in March 1997 (Figure 8 in Pickart et al., 2002). The sea surface heating and eddy-induced lateral buoyancy transport from the WGC, as described later, stratify the Labrador Sea interior in summer (Figures 4a, c). The simulated salinity is vertically homogeneous even in June in the convection region as shown by the isolines of 34.89 and $34.91 \mathrm{~g} \mathrm{~kg}^{-1}$ in salinity (Figure 4c). This qualitative feature of vertical uniformity of salinity is consistent with observations (Pickart et al., 2002; Yashayaev, 2007)

The potential density of LSW ranges between 27.8 and $27.83 \mathrm{~kg} \mathrm{~m}^{-3}$ in our model (Figure 4). The modeled LSW is denser than observed (27.7727.80 in mid 1990s and 27.68-27.77 in 2000s; Figure 5; Yashayaev, 2007). Although the potential temperature of LSW is in the range of observed in- 
terannual variability (Figure 4a and 5a, b), salinity ( 34.9 $\mathrm{g} \mathrm{kg}^{-1}$; Figure 4c) is larger than observed (34.83-34.86 $\mathrm{g} \mathrm{kg}^{-1}$; Figure $\left.5 \mathrm{c}, \mathrm{d}\right)$ by $\sim 0.05 \mathrm{~g} \mathrm{~kg}^{-1}$. Since the salinity in Labrador Sea interior is vertically more uniform than observed (Figure 4c, d), we understand that the vertical mixing induced by deep convection is too strong in our model. In fact, the modeled winter time convection is wider/deeper than observed, and this discrepancy is discussed later (in Section 3.3).

\subsection{Eddies}

The three types of eddies (IR, BCE, CE) proposed by Chanut et al. (2008) are well represented in our model. The IRs (their diameter is 40-50 $\mathrm{km}$ ) are detected by cores of low relative vorticity, sea surface temperature and sea surface salinity (Figures 6a-c). Such cold cores at the sea surface are observed by high resolution satellite remote-sensing data (e.g., ATSR and MODIS). These cores also have relatively high temperature and high salinity in subsurface (Figure 6d). Although this layered structure of IRs is revealed by many previous observational studies (e.g., Hatun et al., 2007; Rykova et al., 2009), previous simulation studies by eddy-resolving models (Chanut et al., 2008; McGeehan and Maslowski, 2011) represented only the high temperature and high salinity feature and did not reproduce the low temperature and low salinity near sea surface. Their time evolution in our model shows that the IRs are first transported by the cyclonic mean flow along isobaths and later propagate to the basin interior. The IRs are longlived (their typical lifetime is several months) and wander in the Labrador Sea interior in our model. Such a feature of the trajectory of IRs is consistent with observations (Prater, 2002; Cuny et al., 2002; Hatun et al., 2007). The 

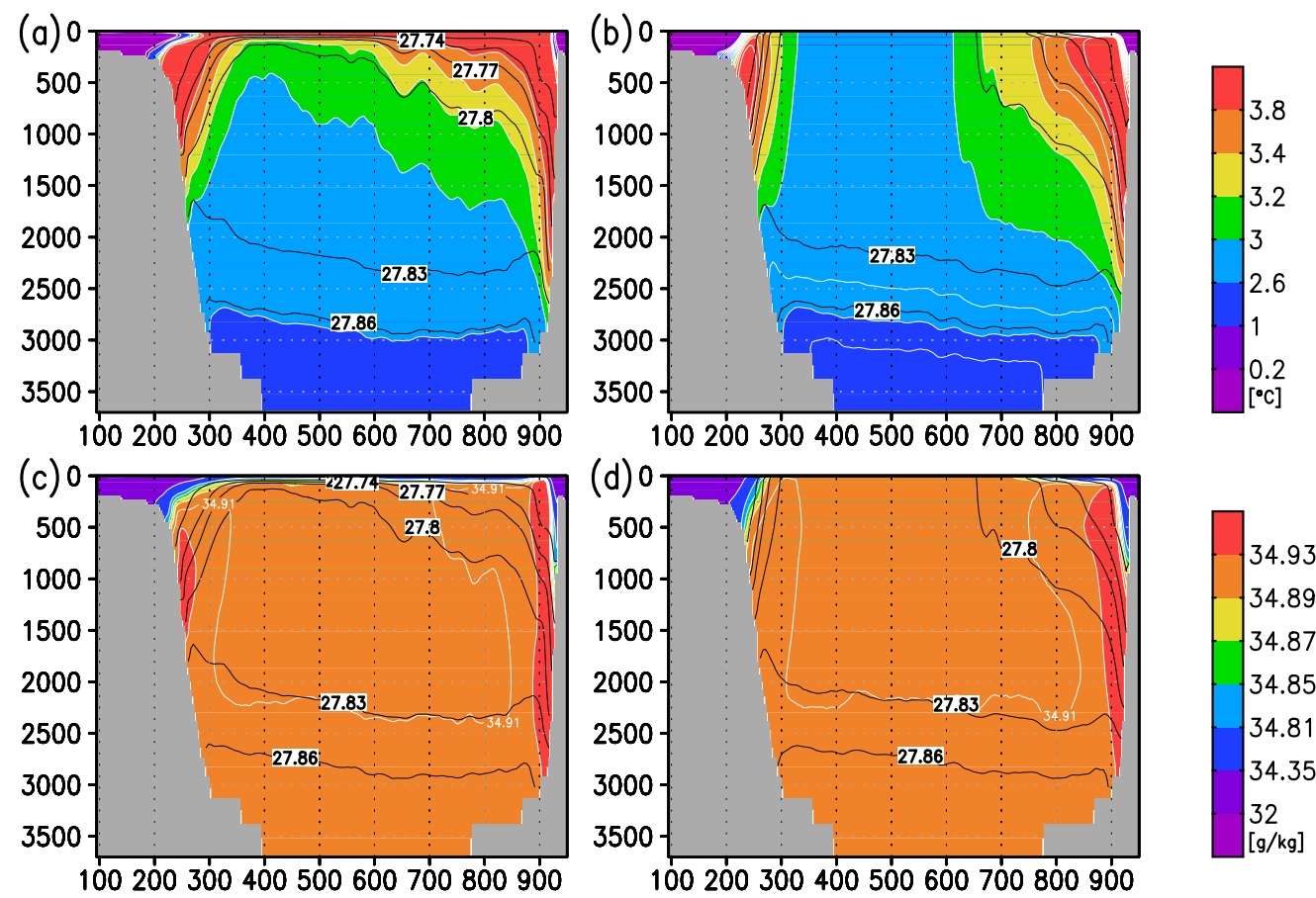

Figure 4: 5-year mean potential temperature (top; ${ }^{\circ} \mathrm{C}$ ), and salinity (bottom; $\mathrm{g} \mathrm{kg}^{-1}$ ) along AR7W. Contours indicate isopycnal surfaces in potential density of 27.68, 27.74, $27.77,27.80,27.83,27.86 \mathrm{~kg} \mathrm{~m}^{-3}$. The colors and contour values are so chosen as to coincide with Figure 5. The left and right panels are for June and March, respectively. The left/right ends are the Labrador Peninsula/Greenland. The horizontal labels indicate the distance from the coast of the Labrador Peninsula $(\mathrm{km})$. 
(a)

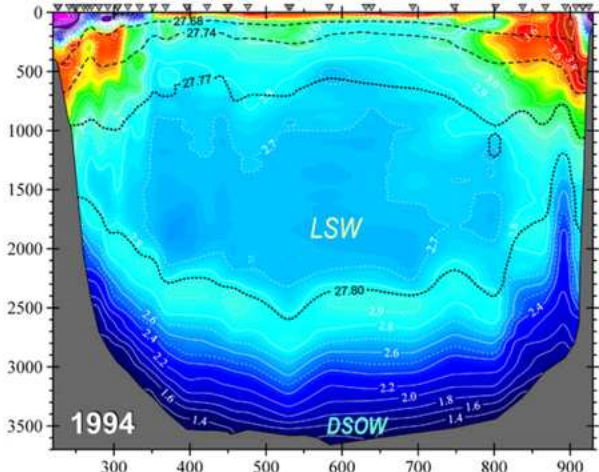

(c)

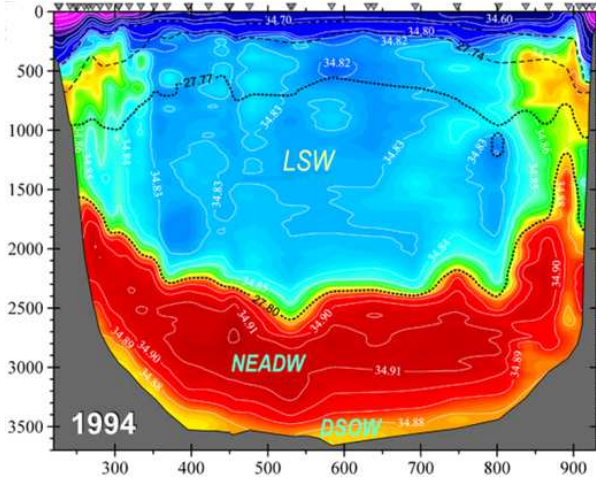

(b)

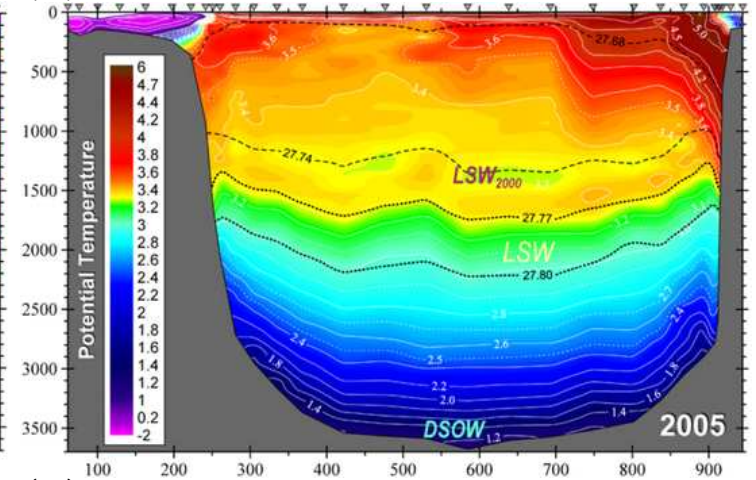

(d)

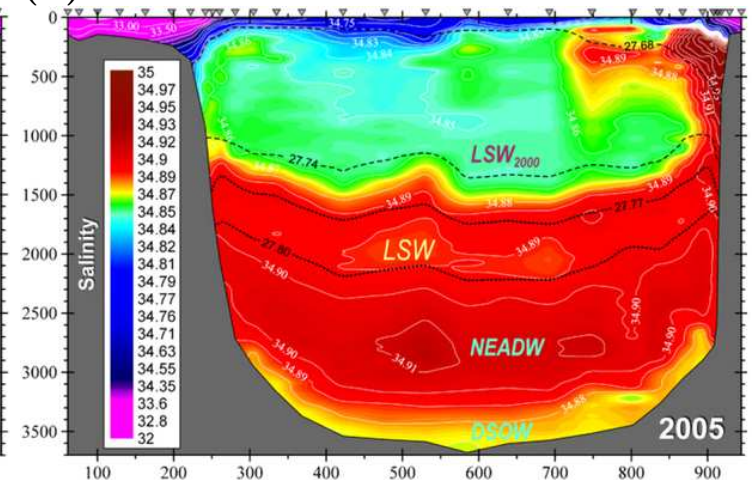

Figure 5: Observed potential temperature (top; ${ }^{\circ} \mathrm{C}$ ) and salinity (bottom; $\mathrm{g} \mathrm{kg}^{-1}$ ) in 1994 (left) and 2005 (right) along AR7W (from Yashayaev, 2007). 
moment of IRs carries the contained buoyancy (warm and fresh water) from the WGC to the interior Labrador Sea.

The BCEs, whose diameter is smaller than that of the IRs (Chanut et al., 2008), are found as the extremal relative vorticity in the vicinity of the whole of the boundary currents (Figures 6a, e). Their time evolution indicates that the BCEs also contain the low density boundary current water and transport buoyancy from the region of the boundary currents to the interior Labrador Sea. Although the number of BCEs is larger than that of IRs, the lifetime of BCEs is shorter than that of IRs.

The CEs (diameter $\sim 10 \mathrm{~km}$ ) are formed from winter to early spring in the Labrador Sea interior and are recognized as frequent small cores of extremal relative vorticity (Figure 6e). It is well known that the CEs are the result of the convection induced by the sea surface cooling and directly and quickly restratify the shallow layer (Jones and Marshall, 1997). As the horizontal grid size of our model is not sufficiently small, eddies smaller than the mesoscale (known as sub-mesoscale eddies) are not resolved. It is likely that mesoscale eddies develop around the deep convection region instead of sub-mesoscale eddies. The resolved mesoscale eddies seem to contribute to the rapid tilting of the steeply sloping isopycnal surfaces in the deep convection area in our model.

The (monthly mean) eddy kinetic energy (EKE) is defined as

$$
\mathrm{EKE}=\frac{1}{2}\left(\overline{u^{\prime 2}}+\overline{v^{\prime 2}}\right),
$$

where overbar denotes the monthly mean, and $\left(u^{\prime}, v^{\prime}\right)$ indicate the deviations of horizontal velocities from the monthly mean velocities $(\bar{u}, \bar{v})$. The horizontal map of annual-mean sea surface EKE is shown in Figure 7a. The 

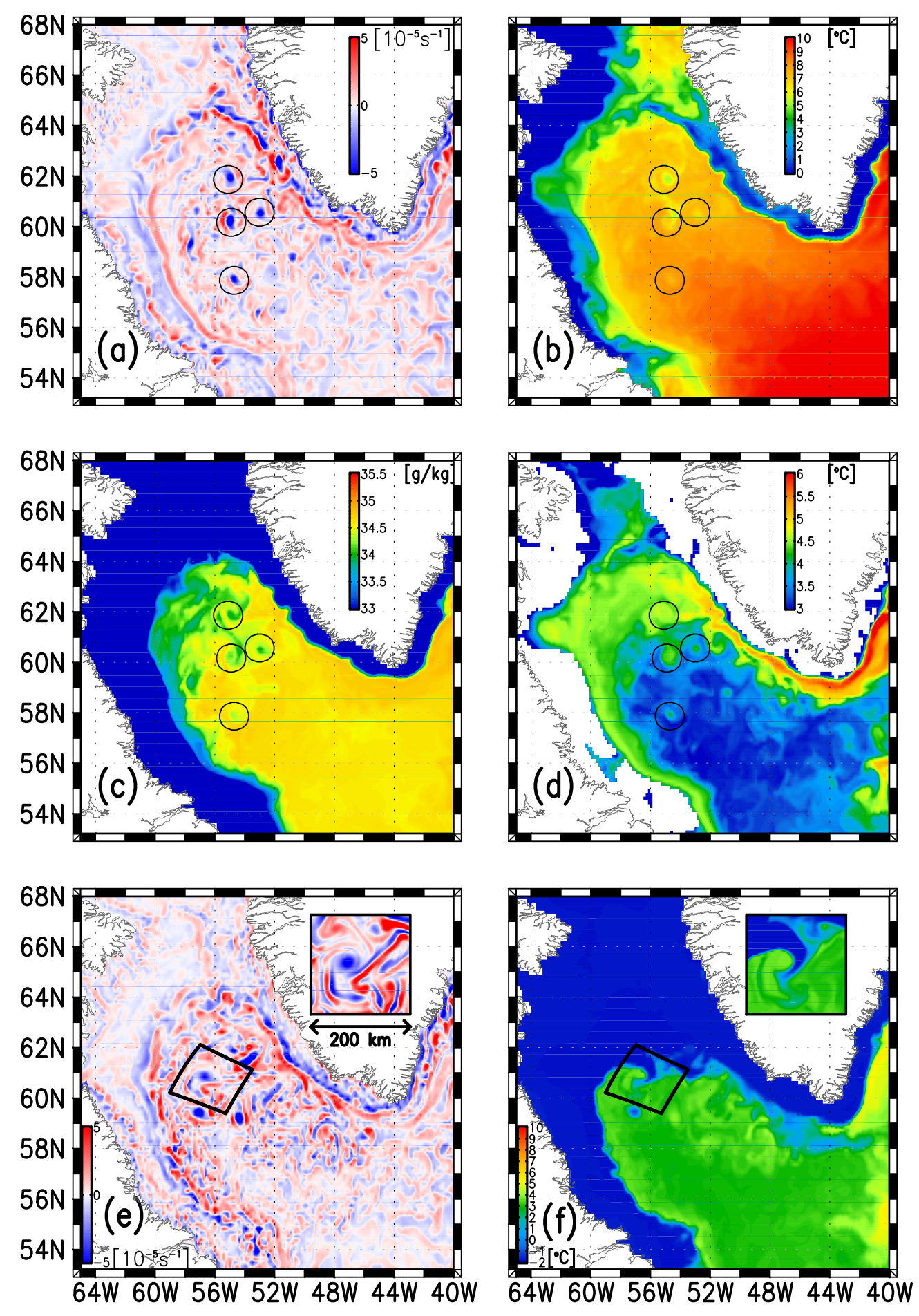

Figure 6: One-day mean of sea surface (a) rePative vorticity, (b) temperature, (c) salinity, and (d) potential temperature at $635 \mathrm{~m}$ depth on 10th July of the eighth year. The units are $10^{-5} \mathrm{~s}^{-1},{ }^{\circ} \mathrm{C}$, and $\mathrm{g} \mathrm{kg}^{-1}$. The black circles in the interior Labrador Sea mark the IRs. The bottom two panels are the same as the top two but on 24th March of the eighth year. Enlarged views for the black boxes are also shown at the upper-right corners in the 
largest EKE is located at the northeastern region and extends toward the interior Labrador Sea. This tongue-like large EKE is also shown by the sea surface variability obtained from TOPEX/Poseidon altimeter (Prater, 2002; Lilly et al., 2003) and previous modeling studies (e.g., Eden and Boning, 2002; Katsman et al., 2004; Chanut et al., 2008; Luo et al., 2011). As the IRs propagate and the CEs are also formed, the EKE in the interior Labrador Sea is largest from winter to spring (Figure not shown), and this seasonal variability is consistent with the satellite observations (Lilly et al., 2003; Brandt et al., 2004). Note that the large EKE off Baffin Island and along the coast of Labrador Peninsula is caused by the sea-ice motion, which induces rapid changes of horizontal velocities near the sea surface.

The tongue of large EKE does not extend to the interior of the Labrador Sea in the SMOOTH case (Figure 7b). As we expected, the IRs cannot develop significantly and do not propagate toward the interior region when the continental slope off the Cape Desolation is smoothed. The effect of the IRs on the deep convection is described in the next section through comparison of the results of the SMOOTH and control cases.

\subsection{Convection}

Figure 7c shows the monthly mean depth of convection in March, when the convection develops most by sea surface cooling. Here, the depth of convection refers to the deepest level which convective adjustment reaches. While it is consistent with observations (Pickart et al., 2002; Lavender et al., 2002) that the deepest convection is found in the southwestern part of the Labrador Sea, both the depth and spatial extent are much larger than observed (Figure 7c). Previous observational studies suggested that the depth 

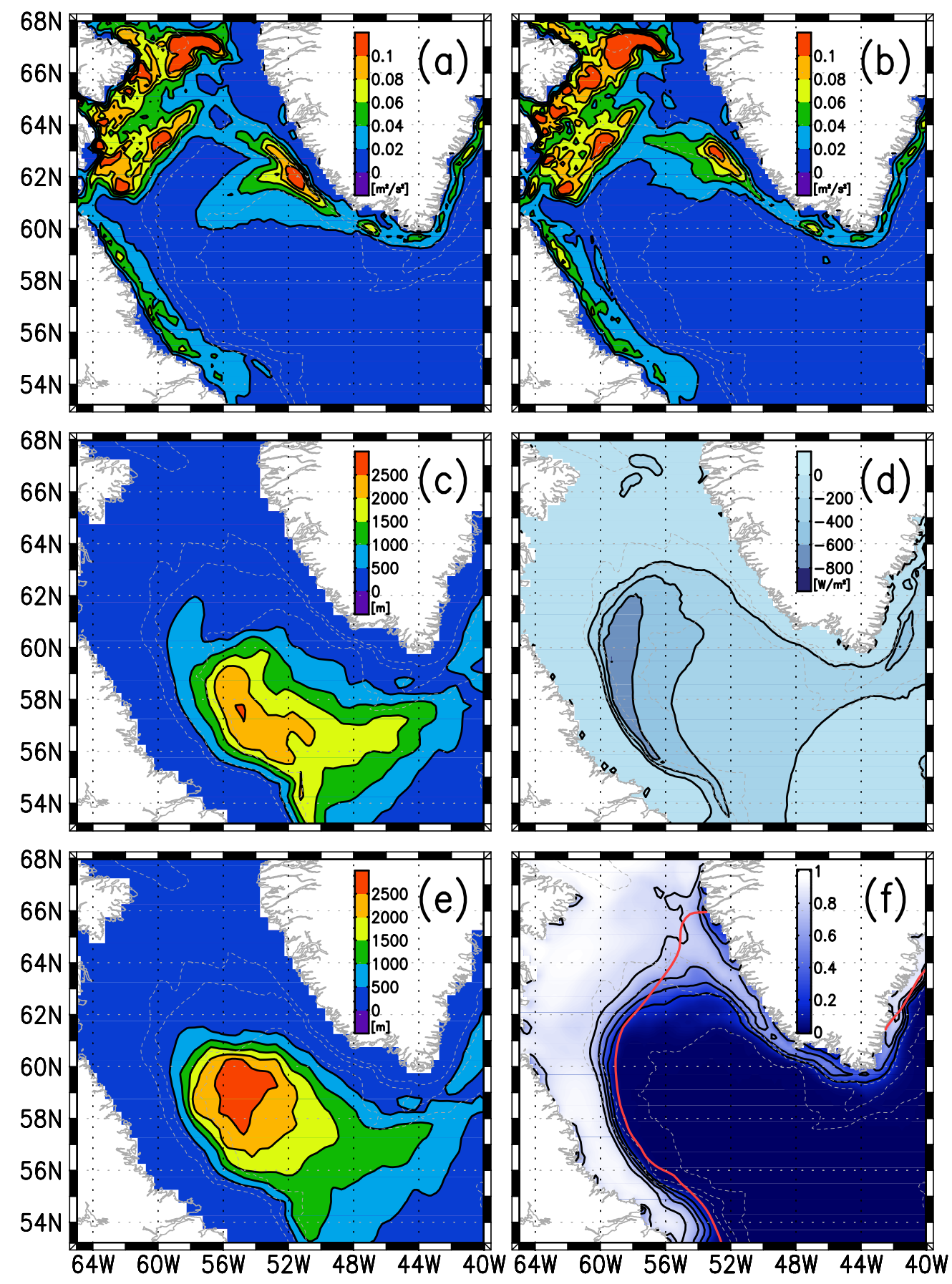

Figure 7: (a) 5-year mean of sea surface eddy kinetic energy $\left(\mathrm{m}^{2} \mathrm{~s}^{-2}\right)$. (b) Same as (a), but in the SMOOTH case. (c) Monthly mean of the depth of convection in March (m). (d) Sea surface heat flux ( $\mathrm{W} \mathrm{m}^{-2}$; positive means downward) averaged from January to March. (e) Same as (c), but in the SMOOTH case. (f) 3-month (from January to March) mean of sea ice concentration. The red line indicates the climatological sea-ice edge from satellite observations. The contour intervals are $0.02 \mathrm{~m}^{2} \mathrm{~s}^{-2}, 500 \mathrm{~m}, 200 \mathrm{~W} \mathrm{~m} \mathrm{~m}^{-2}$, and 0.2 for EKE, convection depth, sea surface heat flux, and sea ice concentration, respectively. 
of convection has large interannual variability (e.g., $2300 \mathrm{~m}$ in 1994-1995 and 1000-1300 m in early and mid-2000s Avsic et al., 2006; Yashayaev, 2007). Pickart et al. (2002) argued that since the hydrographic state was preconditioned by severe winter conditions in early 1990s, even weak cooling caused the deep convection to $\sim 1500 \mathrm{~m}$ depth in March 1997. The simulated depth of convection $(\sim 2000-2500 \mathrm{~m})$ is maximum of the observed range (1000-2300m) and not representative as averaged conditions. Previous modeling studies often simulated too wide and too deep convection even in eddy-resolving cases (e.g., Chanut et al., 2008; McGeehan and Maslowski, 2011). Although the convection of the present result is also too wide/deep compared with observations (Pickart et al., 2002), the present result is somewhat improved compared with these studies.

The weak stratification in the central Labrador Sea accompanied by the wind-driven cyclonic circulation preconditions deep convection to take place in the whole of basin center. In addition, sea surface cooling in winter is strongest in the northwestern interior Labrador Sea (Figure $7 \mathrm{~d}$ ). On the other hand, the winter deep convection is furthest developed in southwestern interior Labrador Sea(Figure 7c). These facts imply that the deep convection is suppressed over the central to northern and eastern interior Labrador Sea by lateral buoyancy transport from boundary current region. The role of eddy-induced buoyancy transport from the WGC on the restratification and suppression of deep convection has been suggested by the observational studies (Pickart et al., 2002; Lilly et al., 2003).

The convection is deeper and wider in the SMOOTH case (Figure 7e) than in the control case (Figure 7c). It reaches more than $2500 \mathrm{~m}$ depth, which is 
larger than the result of control case and the above-mentioned observational estimates. The winter deep convection is not sufficiently inhibited because the IRs do not transport buoyancy toward the basin interior (Figure 7b). The following analysis demonstrates that the suppression of deep convection is caused by IRs.

Sea ice extends in the western and northern boundaries of the Labrador Sea in winter (Figure $7 \mathrm{f}$ ). The ice edge around the western and northern Labrador Sea is similar to the climatological ice edge observed from satellites. McGeehan and Maslowski (2011) suggested that the location of deep convection is affected by the sea ice extent in winter. We conclude that the well-represented sea ice extent is one of the reasons for the correct location of deepest winter convection in our model.

Note that sea ice is also found along the southwestern coast of Greenland, which is not in agreement with observation. This discrepancy does not lead to a significant bias of freshwater transport from the eastern region to the Labrador Sea interior. In addition, the lateral heat and freshwater flux between the boundary current region and the interior ocean by sea ice is significantly smaller than that by seawater in our model (result not shown).

\subsection{Heat/freshwater transport}

In order to investigate the role of eddies in the deep convection, the model's buoyancy budget is analyzed here. Since the transported buoyancy inhibits the deep convection in winter and restratifies the homogenized water columns in summer, the year-round buoyancy transport should be analyzed. Figure 8 shows the 5 -year mean heat budget integrated vertically from the sea surface to the bottom. Heat is lost over the whole of the Labrador Sea 
through the sea surface (Figure 8a). This is essentially due to the sea surface cooling in winter (Figure 7d). In the boundary current region, heat is gained by the mean current (the WGC) and lost by the eddies(Figures 8b, c). On the other hand, the interior Labrador Sea gains heat by mesoscale eddies (Figure 8c). The small residual (Figure 8d) indicates that the the model is well thermally equilibrated during the analyzed period.

The freshwater content $(\mathrm{FW})$ is defined here as

$$
\mathrm{FW}=\int_{\mathrm{V}} \frac{S_{\mathrm{ref}}-S}{S_{\mathrm{ref}}} d \mathrm{~V}
$$

where $\mathrm{V}$ indicates the volume under consideration, $S$ is salinity and $S_{\text {ref }}$ is the reference salinity. The reference salinity is set to $34.8 \mathrm{~g} \mathrm{~kg}^{-1}$, which is the average in the Labrador Sea (Figure 2). The budget of the vertically integrated freshwater content is shown in Figure 9. Because of the melting of sea ice in early spring, the net sea surface freshwater flux is downward around the WGC and LC (Figures 7f, 9a). Several patches of upward freshwater flux along the coast are due to the freezing at coastal polynyas. The large downward sea surface freshwater fluxes along the coasts of Greenland and the Labrador Peninsula correspond to river runoff. Since the surface fresh water flux caused by sea ice does not extend to the interior Labrador Sea, the role of freshwater transport in controlling the deep convection is not affected by the biased distribution of sea ice along the western coast of Greenland (Figure 9a). The WGC transports low salinity water on the west Greenland shelf, and high salinity water (IW) from the Irminger Sea on the continental slope (Figure 9b). Mesoscale eddies transport high salinity water from the WGC toward the coast (Figure 9c). The eddy-induced transport of high or low salinity water does not extend to the interior Labrador Sea when vertically 


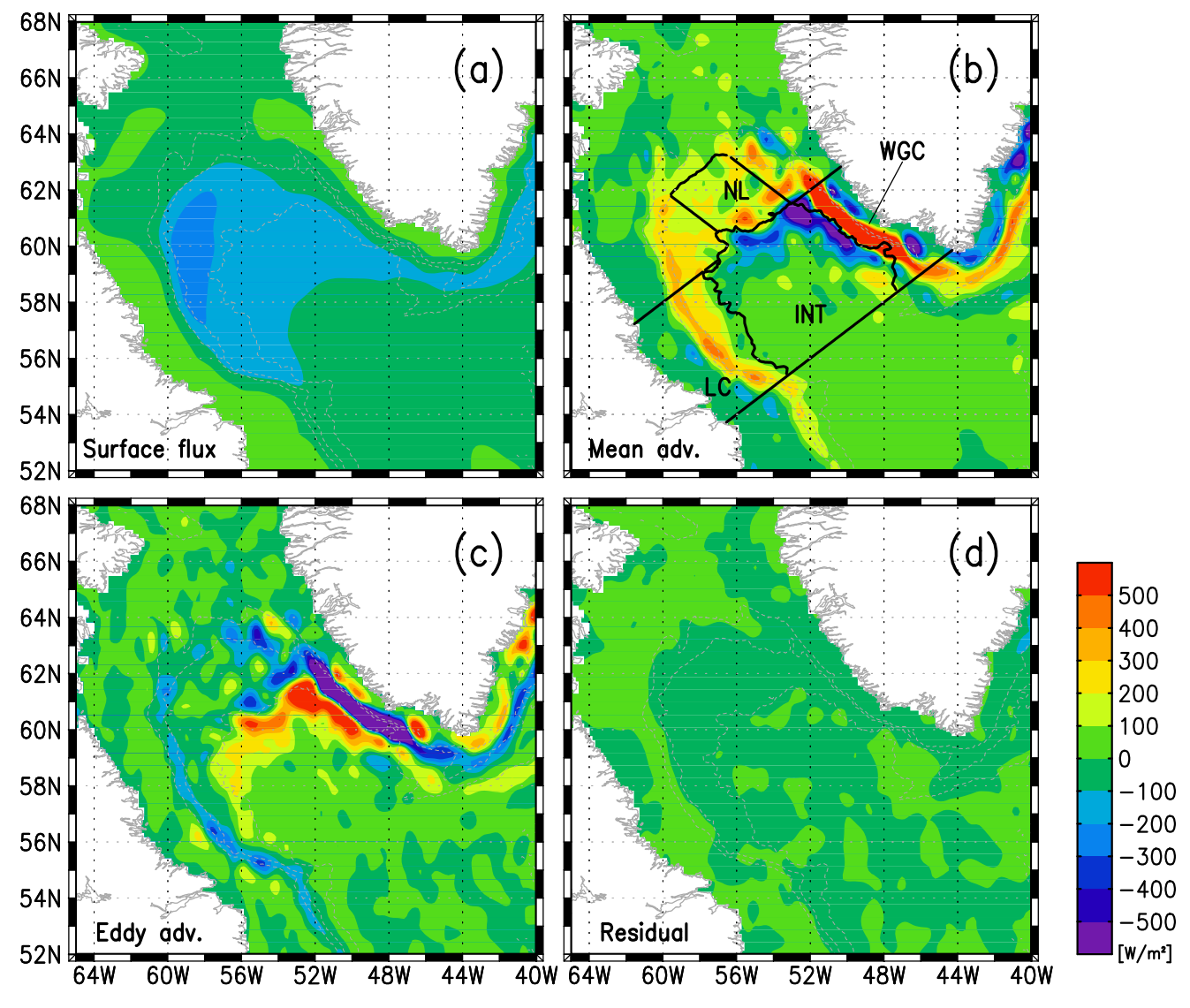

Figure 8: Components in 5-year mean vertically integrated heat budget. (a) Sea surface flux, (b) mean advection, (c) eddy, and (d) residual. The positive and negative values mean the local heat gain and loss, respectively. The four boxes (WGC: West Greenland Current, NL: North Labrador Sea, INT: Labrador Sea interior, and LC: Labrador Current) are defined for quantitative analysis. 


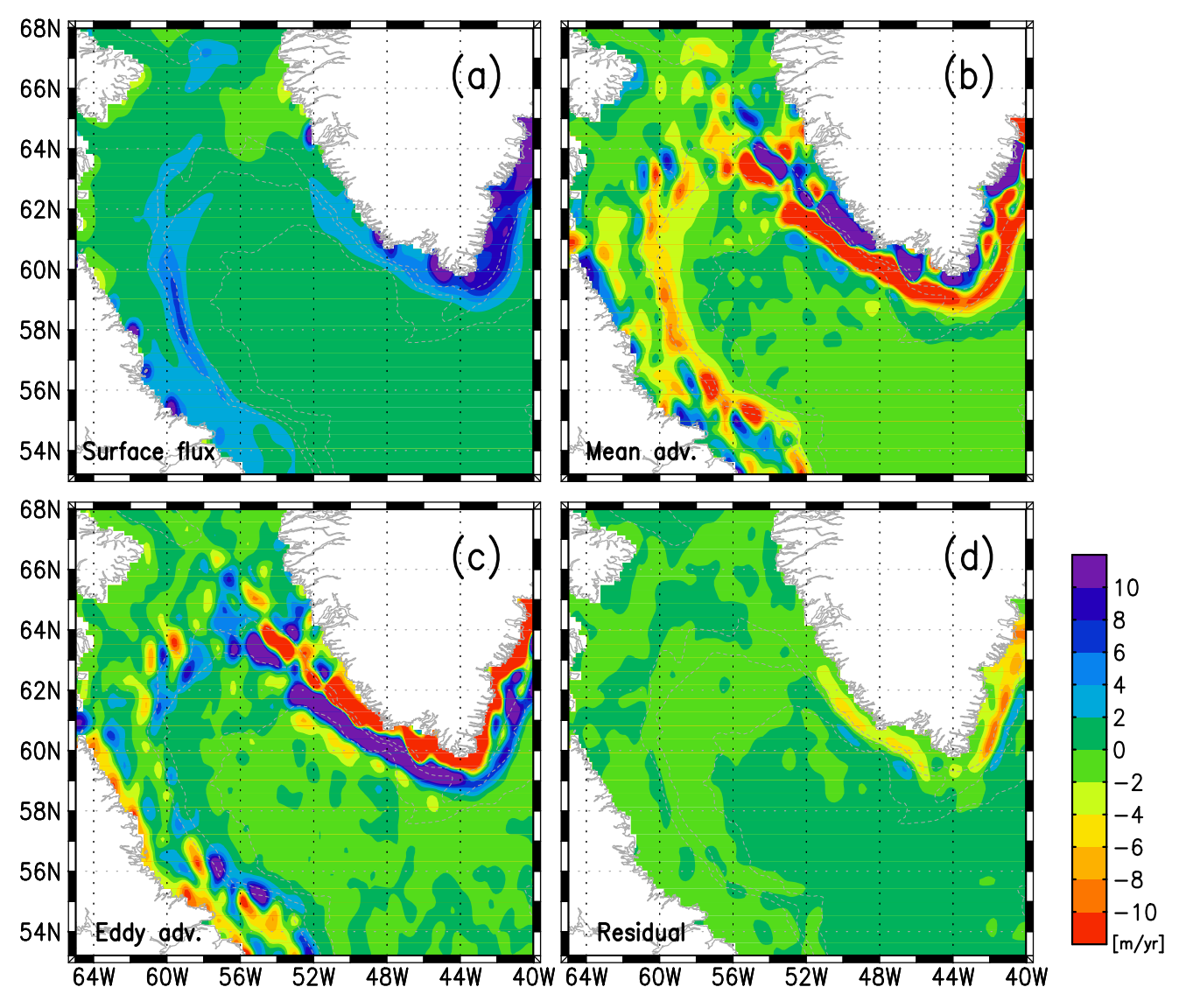

Figure 9: Same as in Figure 8 but for freshwater budget.

integrated over the whole depth, since the transport of fresher water in the surface layer and that of saltier water in the subsurface layer cancel each other (Figure 9c). The small residual (Figure 9d) means that freshwater content is well equilibrated during the analyzed period in the Labrador Sea. The heat and freshwater budgets in four regions (the boxes labeled as WGC, NL, INT, and LC in Figure 8) are shown in Table 1. In the WGC (West Greenland Current) box, the WGC imports seawater from the Irminger 
Sea. In the NL (North Labrador) box, the WGC and large EKE, which indicates active IRs, exist. The INT (interior) box corresponds to the area whose bottom is deeper than $3000 \mathrm{~m}$ in the central Labrador Sea. The LC (Labrador Current) box is the western boundary of the Labrador Sea, where EKE is not significantly large (less than $0.02 \mathrm{~m}^{2} \mathrm{~s}^{-2}$ ) except for the noise accompanied by sea ice formation or melting near the Labrador coast.

Heat is injected to the WGC box by the WGC (mean advection; 374 $\left.\mathrm{W} \mathrm{m}^{-2}\right)$ and exported by eddies $\left(-343 \mathrm{~W} \mathrm{~m}^{-2}\right)$. In contrast, in the $\mathrm{LC}$ box the heat carried in by mean advection (the $\mathrm{LC} ; 78 \mathrm{~W} \mathrm{~m}^{-2}$ ) is removed not by eddies $\left(-5 \mathrm{~W} \mathrm{~m}^{-2}\right)$ but by sea surface cooling $\left(-74 \mathrm{~W} \mathrm{~m}^{-2}\right)$. This is consistent with the result that the eddy activity is small in the western boundary (LC box side) than in the eastern boundary (WGC box side). In the INT box, almost all heat injected by the eddies $\left(152 \mathrm{~W} \mathrm{~m}^{-2}\right)$ is lost by winter sea surface cooling $\left(-115 \mathrm{~W} \mathrm{~m}^{-2}\right)$. In the $\mathrm{NL}$ box, the warm water (IW) advected by the WGC $\left(183 \mathrm{~W} \mathrm{~m}^{-2}\right)$ is mainly cooled at the sea surface $\left(-154 \mathrm{~W} \mathrm{~m}^{-2}\right)$. At an observational point in the central Labrador Sea $\left(53^{\circ} \mathrm{W}\right.$, $\left.56^{\circ} \mathrm{N}\right)$, the annual mean surface heat loss $\left(-100 \mathrm{~W} \mathrm{~m}^{-2}\right)$ is much larger than an estimate based on a reanalysis data $\left(-28 \mathrm{~W} \mathrm{~m}^{-2}\right.$; Straneo, 2006). This discrepancy is accompanied with the too wide/deep convection in the central Labrador Sea, and it is discussed later.

In the WGC and LC boxes, the freshwater supplied through the sea surface (389 and $232 \mathrm{~cm} \mathrm{year}^{-1}$ ) is exported by the mean advection (-434 and $-239 \mathrm{~cm}$ year ${ }^{-1}$ ). In the WGC box, removal by eddies of high-salinity water originating from the Irminger Sea $\left(86 \mathrm{~cm}\right.$ year $\left.{ }^{-1}\right)$ is also large. In the LC box, the eddy-induced freshwater transport $\left(23 \mathrm{~cm} \mathrm{year}^{-1}\right)$ is very small 
Table 1: The area-averaged budgets of heat $\left(\mathrm{W} \mathrm{m}^{-2}\right)$ and freshwater $\left(\mathrm{cm} \mathrm{year}^{-1}\right)$ by sea surface flux, vertically integrated mean advection, eddies, and total (trend) in four boxes (WGC: West Greenland Current, NL: North Labrador, INT: Labrador Sea interior, and LC: Labrador Current) defined in Figure 8b. The values to the left and right of the slash indicate the heat and freshwater, respectively.

\begin{tabular}{|c|c|c|c|c|}
\hline Heat / Freshwater & WGC & NL & INT & $\mathrm{LC}$ \\
\hline Surface flux & $-39 / 389$ & $-154 / 111$ & $-115 / 40$ & $-74 / 232$ \\
\hline Mean advection & $374 /-434$ & $183 /-119$ & $-42 / 10$ & $78 /-239$ \\
\hline Eddy advection & $-343 / 86$ & $-51 / 41$ & $152 /-61$ & $-5 / 23$ \\
\hline Total (Trend) & $-9 / \quad 42$ & $-22 / 33$ & $-5 /-11$ & $-2 / 16$ \\
\hline
\end{tabular}

because of the low activity of eddies, similarly to the heat transport. In the NL box, the sea surface freshwater injection caused by the melting of sea ice transported through the Davis Strait $\left(111 \mathrm{~cm} \mathrm{year}^{-1}\right)$ is exported by mean advection $\left(-119 \mathrm{~cm} \mathrm{year}^{-1}\right)$. In the INT box, precipitation supplies freshwater $\left(40 \mathrm{~cm}\right.$ year $\left.^{-1}\right)$ and high salinity water is supplied from the WGC box by eddies $\left(-61 \mathrm{~cm} \mathrm{year}^{-1}\right)$.

The buoyancy budget over the whole water column does not necessarily account for stabilization of the water column. Buoyancy injection near the sea surface stabilizes a water column, while that at depth destabilizes it. Therefore, it is more relevant to focus on the upper layer in order to reveal the role of buoyancy transport in inhibition of deep convection and restratification of homogenized water columns.

Figure 10 shows the components of the heat and freshwater budget due to horizontal motion in the layer shallower than $120 \mathrm{~m}$, where low salinity 
447

448

water is contained along the WGC. The mean flow transports low salinity water toward the region bounded by 2000 and $3000 \mathrm{~m}$ isobaths in the north Labrador Sea (the NL box; Figures 10a, c). High temperature / low salinity water, which indicates the influence of WGC, is transported by eddies and extends toward the northern part of the interior (deeper than $3000 \mathrm{~m}$ ) Labrador Sea (Figures 10b, d).

The heat originating from the atmosphere in summer is transported by eddies in the northeastern part of the interior Labrador Sea, where the winter convection is restricted by eddy activity (Figures 7a-c, e). The mean flow and eddies advect low salinity water from the WGC region to the north and northern part of the interior Labrador Sea, where consequently the deep convection is suppressed in spite of the strong sea surface cooling in winter (Figure $7 \mathrm{c}, \mathrm{d}$ ). As the surface low salinity water is colder than the buoyant water of the IW, it efficiently prevents the deep water from being cooled by the atmosphere. We find that both heat and freshwater transports work to stabilize the interior Labrador Sea. Next, we compare relative contributions from heat and freshwater.

\subsection{Buoyancy transport}

Buoyancy relative to a reference state, $\mathrm{B}$, is decomposed into thermal and haline parts, $\mathrm{B}_{\theta}$ and $\mathrm{B}_{S}$, respectively, and they are defined here as

$$
\mathrm{B}_{\theta}=-g \alpha \Delta \theta
$$

$$
\mathrm{B}_{S}=g \beta \Delta S,
$$

$$
\alpha(\theta, S, P)=\frac{\partial \rho}{\partial \theta}, \beta(\theta, S, P)=-\frac{\partial \rho}{\partial S}
$$




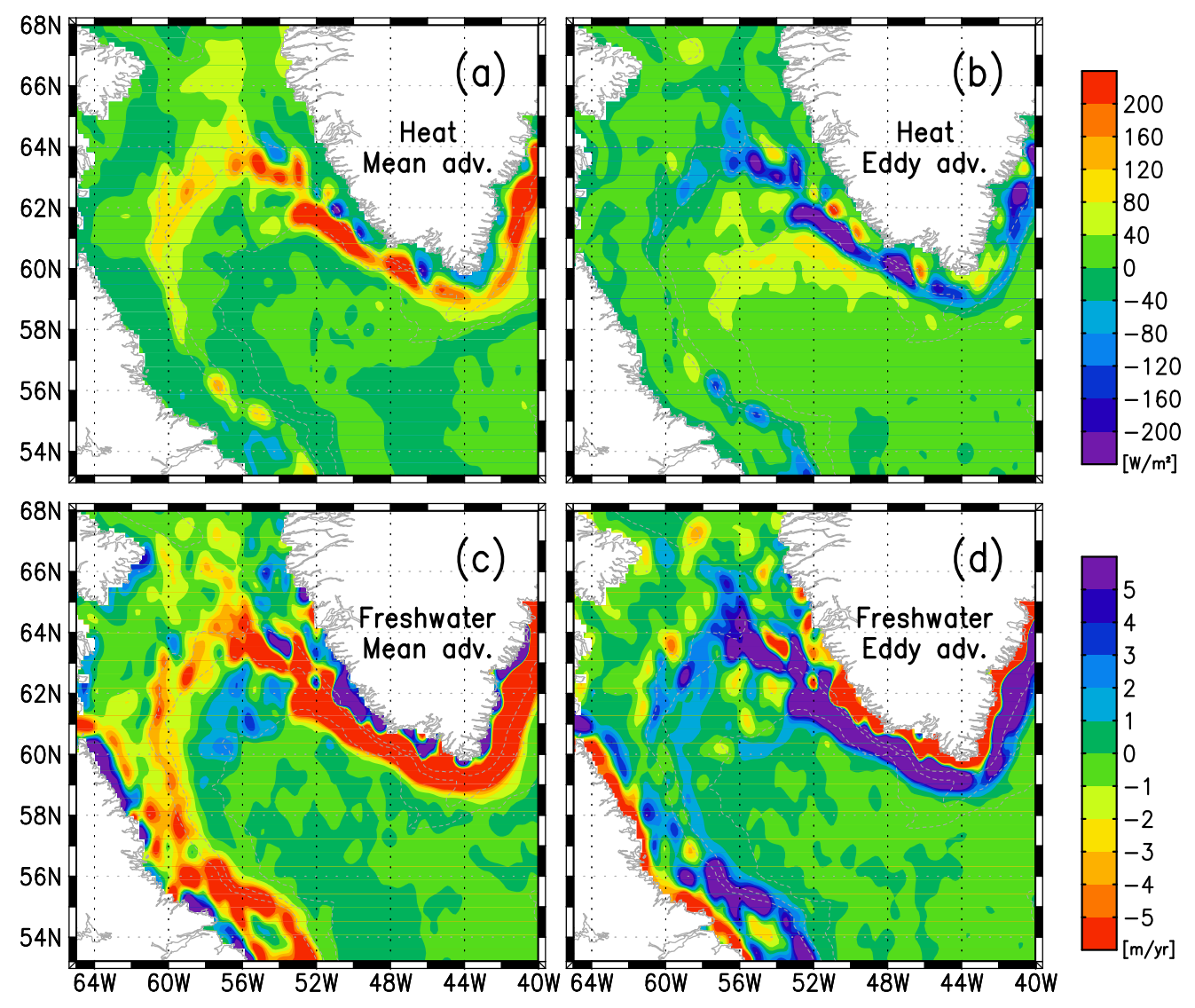

Figure 10: Same as Figures 8b, c (upper panels) and 9b, c (lower panels), but vertically integrated only in the upper ocean $(<120 \mathrm{~m})$. 
where $\Delta \theta$ and $\Delta S$ are anomalies of potential temperature and salinity, respectively, from the reference state, $g$ is acceleration of gravity, $P$ is pressure, $\rho$ is potential density. In the buoyancy budget of the whole water column, the total advection (mean and eddy) provides buoyancy by heat (Figure 11a) in almost all regions. Buoyancy is lost by high salinity water (IW) in the interior ocean, while it is gained by the low salinity water originated in the WGC, LC, and river runoff around the continental margin (Figure 11b). The boundary current (mean advection) injects buoyancy due to heat (Figure 11c). The freshwater is injected by boundary current along the coasts, especially along the western coast of Greenland, and freshwater content is decreased along continental slope around the WGC and LC boxes where IW is transported (Figures 11d). Eddies transport heat and high salinity water from the boundary current region in the WGC box to the Labrador Sea interior (INT box) (Figure 11e, f). It is due to eddy activity that heat and salinity transport is larger in the northeastern Labrador Sea interior than in the southwestern Labrador Sea interior.

A quantitative comparison (Table 2) shows that the whole-column gain or loss of heat (temperature) contributes more to the buoyancy budget than that of freshwater (salinity) over the whole Labrador Sea. For instance, in the INT box, the buoyancy imported by heat $\left(661 \times 10^{4} \mathrm{~N} \mathrm{~s}^{-1}\right)$ is about 17 times larger than the buoyancy lost by high salinity water $\left(-38 \times 10^{4} \mathrm{~N} \mathrm{~s}^{-1}\right)$. Even considering mean and eddy advection separately, freshwater does not contribute to the buoyancy budget in the Labrador Sea for the whole-column view.

The lower part of Table 2 shows the buoyancy budget in the near surface 

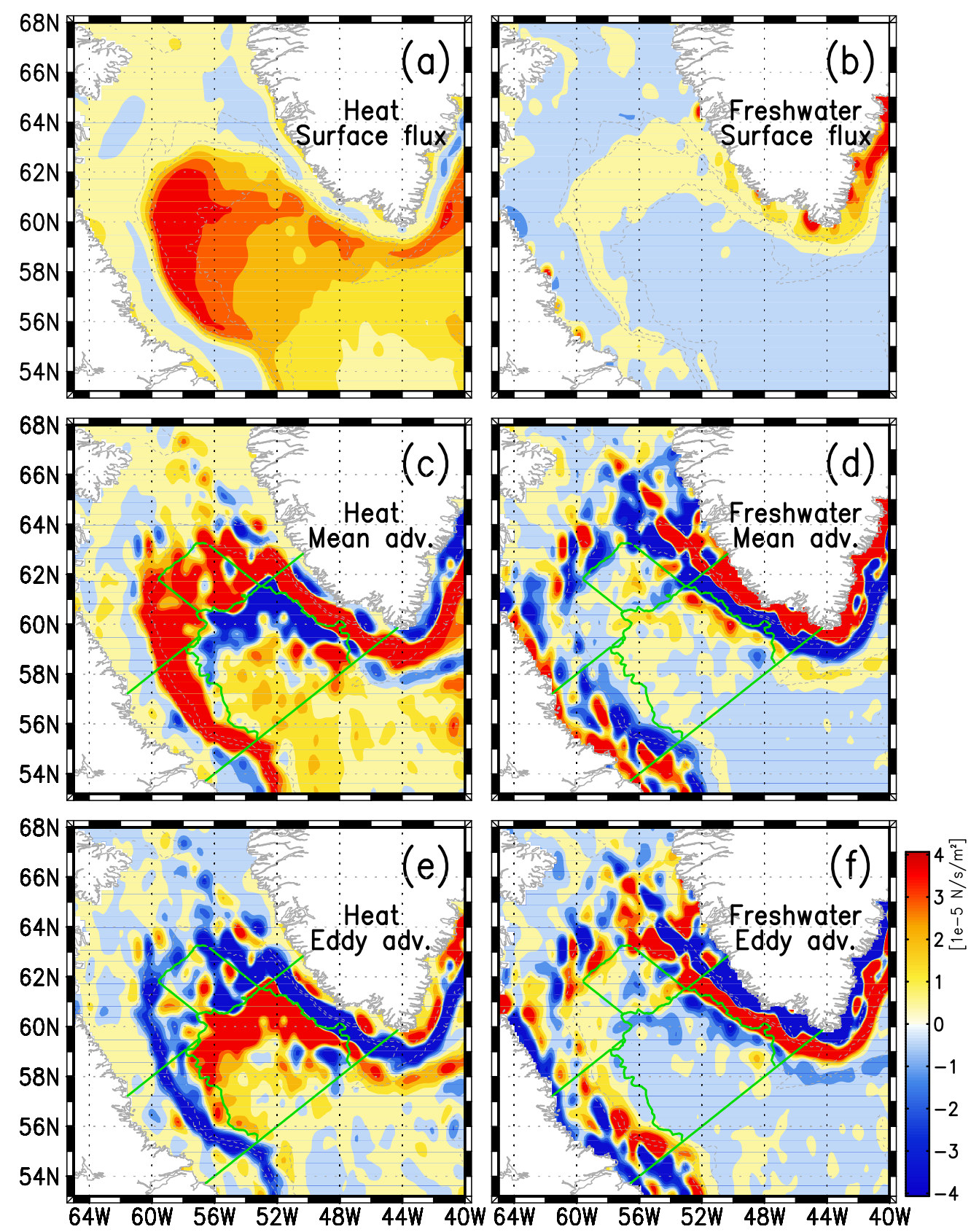

Figure 11: Distribution of thermal contribution to the vertically integrated gain or loss of buoyancy over the whole column by (a) total of mean advection and eddy, (c) mean advection, and (e) eddy. (b), (d), and (f) are same as (a), (c), and (e), respectively, but for haline contribution. 
Table 2: Budget of volume integrated buoyancy $\left(10^{4} \mathrm{~N} \mathrm{~s}^{-1}\right)$ by mean advection, and eddies in four boxes (WGC: West Greenland Current, NL: North Labrador, INT: Labrador Sea interior, and LC: Labrador Current) defined in Figure 8b. The values to the left and right of the slash indicate the thermal and haline buoyancy budget, respectively.

\begin{tabular}{|c|c|c|c|c|}
\hline Heat / Freshwater & WGC & NL & INT & $\mathrm{LC}$ \\
\hline Total advection & $69 / \quad 46$ & $199 / 14$ & $661 /-38$ & $311 / 10$ \\
\hline Mean advection & $1009 /-39$ & $316 /-8$ & $-292 / 82$ & $441 /-26$ \\
\hline Eddy advection & $-940 / 85$ & $-116 / 22$ & $952 /-119$ & $-100 / 36$ \\
\hline Total adv. $(<120 \mathrm{~m})$ & $57 / 46$ & $69 / 100$ & $199 / 73$ & $42 / 98$ \\
\hline Mean adv. $(<120 \mathrm{~m})$ & $242 /-332$ & $42 / 91$ & $7 / \quad 14$ & $22 /-64$ \\
\hline Eddy adv. $(<120 \mathrm{~m})$ & $-185 / 378$ & $27 / \quad 9$ & $192 / 58$ & $20 / 162$ \\
\hline
\end{tabular}

layer (above $120 \mathrm{~m}$ depth). In WGC box, both heat and freshwater comparably (57 and $46 \times 10^{4} \mathrm{~N} \mathrm{~s}^{-1}$, respectively) contribute to the buoyancy injection in the total advection (mean plus eddy) (Figures 12a, b and Table 2). In the NL and LC boxes, the freshwater contribution to the buoyancy (100 and $98 \times 10^{4} \mathrm{~N} \mathrm{~s}^{-1}$, respectively) is larger than that induced by heat (69 and $42 \times 10^{4} \mathrm{~N} \mathrm{~s}^{-1}$, respectively). In the north Labrador Sea (NL box), the freshwater and heat by mean advection mainly causes the buoyancy gain in the surface layer (Figures 12d, e). Quantitative comparison (Table 2) shows that the buoyancy injection by mean advection of freshwater $\left(91 \times 10^{4} \mathrm{~N}\right.$ $\left.\mathrm{s}^{-1}\right)$ is twice as large as that by mean advection of heat $\left(42 \times 10^{4} \mathrm{~N} \mathrm{~s}^{-1}\right)$. In the LC box, the surface layer buoyancy gain is mainly contributed from the eddy-induced freshwater injection $\left(162 \times 10^{4} \mathrm{~N} \mathrm{~s}^{-1}\right)$.

In the INT box, the thermal buoyancy gain $\left(199 \times 10^{4} \mathrm{~N} \mathrm{~s}^{-1}\right)$ is about 
three times larger than the haline buoyancy gain $\left(73 \times 10^{4} \mathrm{~N} \mathrm{~s}^{-1}\right)$ for the total advection. However, while the eddy-induced thermal buoyancy transport spreads over the whole Labrador Sea interior, the eddy-induced haline buoyancy transport is confined to the northern Labrador Sea interior (Figures $12 \mathrm{e}, \mathrm{f})$. Thus, we calculate the buoyancy budget by separating the INT box into northern $\left(\operatorname{INT}_{\mathrm{N}}\right)$, eastern $\left(\mathrm{INT}_{\mathrm{E}}\right)$, and southwestern (INT $\mathrm{Sw}$ ) parts (Table 3). In the northern interior $\left(\mathrm{INT}_{\mathrm{N}}\right)$, although the total advection mainly transports buoyancy by heat $\left(67 \times 10^{4} \mathrm{~N} \mathrm{~s}^{-1}\right)$ rather than freshwater $\left(28 \times 10^{4} \mathrm{~N} \mathrm{~s}^{-1}\right)$, the eddy-transported buoyancy by freshwater $\left(44 \times 10^{4} \mathrm{~N}\right.$ $\left.\mathrm{s}^{-1}\right)$ is comparable to the total heat contribution $\left(67 \times 10^{4} \mathrm{~N} \mathrm{~s}^{-1}\right)$. In the eastern part of the interior Labrador Sea $\left(\mathrm{INT}_{\mathrm{E}}\right)$, the injection of buoyancy by heat $\left(91 \times 10^{4} \mathrm{~N} \mathrm{~s}^{-1}\right)$ is much larger than that by freshwater $\left(20 \times 10^{4} \mathrm{~N}\right.$ $\mathrm{s}^{-1}$ ) even above $120 \mathrm{~m}$ depth. In the $\mathrm{INT}_{\mathrm{SW}}$ box, where the deepest convection develops in winter, the eddy-induced heat transport $\left(46 \times 10^{4} \mathrm{~N} \mathrm{~s}^{-1}\right)$ mainly contributes to the buoyancy gain, and that caused by mean advection of freshwater is small $\left(17 \times 10^{4} \mathrm{~N} \mathrm{~s}^{-1}\right)$. The result shows that the fraction of haline contribution is further significant in the northern part of the interior than that in the eastern and southwestern parts. Note that in the $\mathrm{INT}_{\mathrm{N}}$ box, if we calculate the buoyancy above $70 \mathrm{~m}$ depth, eddy-induced contribution of freshwater $\left(46 \times 10^{4} \mathrm{~N} \mathrm{~s}^{-1}\right)$ is larger than that of heat $\left(36 \times 10^{4} \mathrm{~N} \mathrm{~s}^{-1}\right)$ (Table not shown).

McGeehan and Maslowski (2011) explained that unrealistic deepening of winter convection in the northern Labrador Sea in their model is due to shortage of the freshwater along the western coast of Greenland. Chanut et al. (2008) reported that the convection in the northern Labrador Sea is 
Table 3: Budget of volume integrated buoyancy $\left(10^{4} \mathrm{~N} \mathrm{~s}^{-1}\right)$ by mean advection, and eddies above $120 \mathrm{~m}$ depth in three boxes in the INT box defined in Figure 12a. The values to the left and right of the slash indicate the thermal and haline buoyancy budget, respectively.

\begin{tabular}{crrrr}
\hline \hline Heat / Freshwater & INT $_{\mathrm{N}}$ & \multicolumn{2}{c}{ INT $_{\mathrm{E}}$} & \multicolumn{2}{c}{ INT $_{\mathrm{SW}}$} \\
\hline Total adv. & $67 / 28$ & $91 / 20$ & $41 /$ & 24 \\
\hline Mean adv. & $-8 /-15$ & $20 / 13$ & $-5 /$ & 17 \\
\hline Eddy adv. & $75 / 44$ & $71 / 8$ & $46 /$ & 7 \\
\hline \hline
\end{tabular}

suppressed by the heat originating in the IW and transported by the IRs in their model. However, as they did not represent the low salinity core in IRs originating in the WGC, contribution of freshwater to the supply of buoyancy was neglected. This study directly points out that the contribution of freshwater to inhibiting the convection is important in the northern Labrador Sea for the first time.

\section{Discussion and conclusion}

We investigated the relationship between the deep convection and buoyancy budget in the Labrador Sea by using a realistically configured eddyresolving OGCM. In particular, the importance of near surface freshwater transport from the vicinity of the WGC is revealed for the first time. The mean currents and qualitative features of seasonal cycle of temperature and salinity are well simulated by the model. The near surface water of relatively low temperature and salinity in the WGC, which is not reproduced in previous models, is realistically represented. The three types of eddies, which are specified in previous studies, are also well reproduced. The IRs and BCEs 

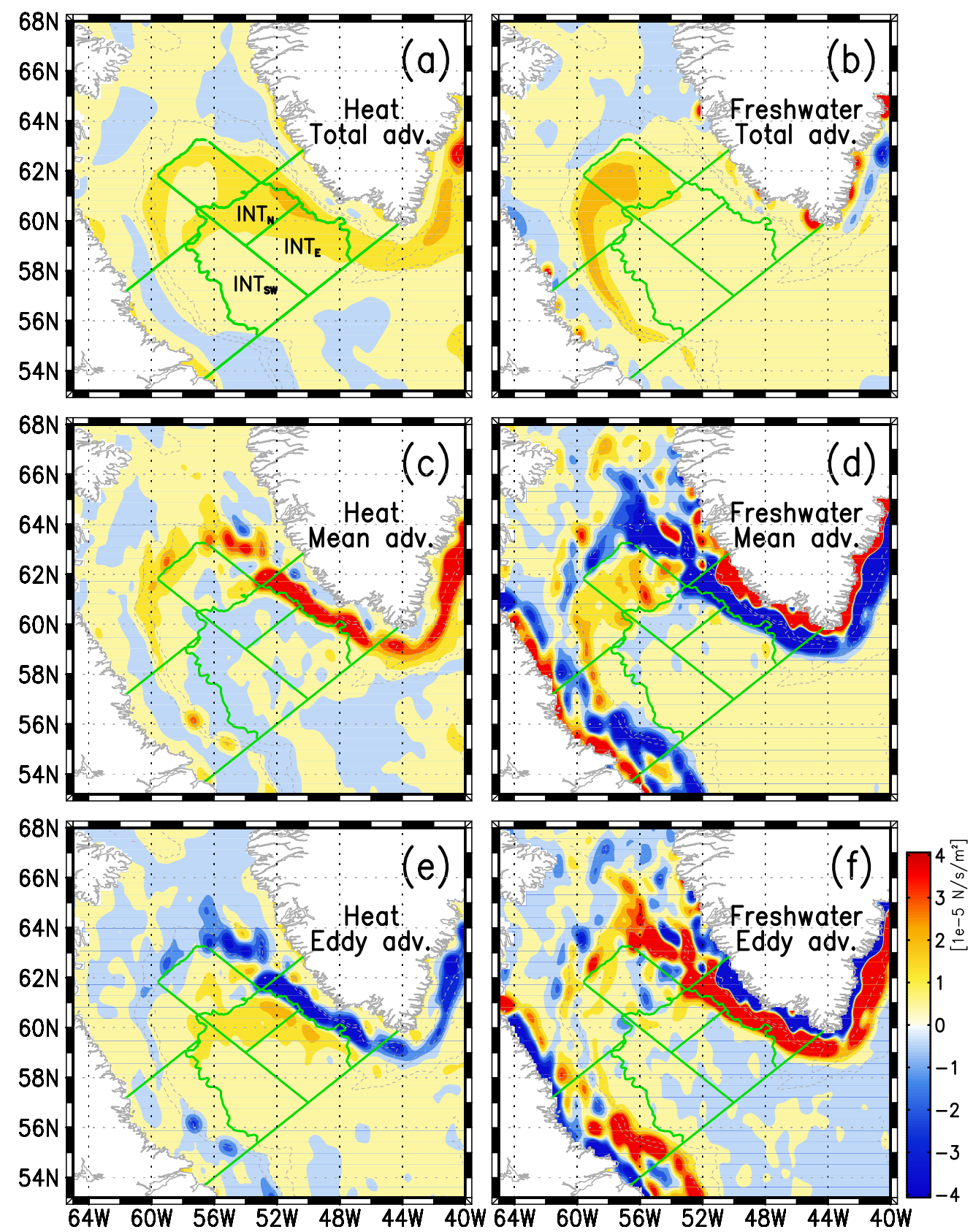

Figure 12: Same as Figure 11, but vertically integrated above $120 \mathrm{~m}$ depth. Three boxes in INT box $\left(\mathrm{INT}_{\mathrm{N}}\right.$ : northern INT, INT : eastern INT, and $\mathrm{INT}_{\mathrm{SW}}$ : southwestern INT) are defined for the qualitative analysis. 
contain relatively low density water of the boundary currents and transport buoyancy by moving to the interior of the Labrador Sea. It is consistent with observations that the winter convection is confined to the southwestern Labrador Sea. As the deep convection unrealistically extends over the whole of Labrador Sea in the comparative experiment (the SMOOTH case) without propagation of the IRs, it is confirmed that the buoyancy transport by the IRs is crucial in inhibiting the winter deep convection. The lateral buoyancy transport caused by heat is significantly larger than that by freshwater for the whole water column in our model. However, it is demonstrated that freshwater mainly contributes to the buoyancy transport near the sea surface in the northern Labrador Sea.

A previous modeling study (McGeehan and Maslowski, 2011) failed to represent the low salinity water along the western coast of Greenland, and winter deep convection drastically and unrealistically developed in the northern Labrador Sea therein. Myers and Donnelly (2008) examined the roles of sea surface heat and freshwater fluxes in the interannual variability of formation of LSW, and they concluded that the buoyancy induced by freshwater is smaller than heat. We studied the effect of both lateral transport and sea surface flux of heat and freshwater on the buoyancy in the central Labrador Sea, and the role of freshwater is not smaller than heat near the sea surface in the northern Labrador Sea. The freshwater provided in the upper $100 \mathrm{~m}$ of the interior Labrador Sea from March to September is $\sim 30 \mathrm{~cm}$ in our result, which is half of observational estimates (Lazier, 1980; Khatiwala et al., 2002). Existence of low salinity water near the sea surface would reduce oceanic heat loss under cold air because strong neat surface stratification 
prevents heat uptake from depth and the sea surface is cooled immediately, as suggested by Gelderloos et al. (2012). Then, it is naturally expected that winter convection does not develop in the northern Labrador Sea even under the influence of the strong cold winds from the continent. If the model's underestimation of lateral freshwater flux is corrected, reproducibility of deep convection might be drastically improved.

The modeled annual mean surface heat loss $\left(-100 \mathrm{~W} \mathrm{~m}^{-2}\right)$ in the central Labrador Sea $\left(53^{\circ} \mathrm{W}, 56^{\circ} \mathrm{N}\right.$; corresponding to the ocean weather station Bravo) is much larger than an estimate based on reanalysis data $\left(-28 \mathrm{~W} \mathrm{~m}^{-2}\right.$; Straneo, 2006). On the other hand, van Aken et al. (2011) estimated a larger heat loss, $-67 \mathrm{~W} \mathrm{~m}^{-2}$, and discussed that such a magnitude is necessary for explaining the interannual variability of LSW temperature. Thus, the actual magnitude of annual mean heat flux is still controversial. The value $-67 \mathrm{~W}$ $\mathrm{m}^{-2}$ is closer to the result of our model. However, the modeled heat loss is still significantly larger and would be associated with the simulated stronger deep convection compared with observation. As the CEs, which actually are sub-mesoscale and rapidly tilt the steeply sloping isopycnal surfaces around deep convection, are not sufficiently resolved, the mesoscale eddies function as their substitute in our model. If sub-mesoscale eddies were resolved, the winter convection might be more efficiently suppressed. We should directly resolve such small eddies or use parameterizations of sub-mesoscale eddies (Fox-Kemper et al., 2008; Fox-Kemper and Ferrari, 2008) for better representing restratification of winter deep convection and heat loss in the central Labrador Sea. It is likely that the too strong sea surface cooling and development of convection enhance eddy activities through a large horizontal 
density gradient and thus strong baroclinicity. It may be the case that the lateral buoyancy (both heat and freshwater) flux is overestimated by such a bias. However, our main conclusion that the role of freshwater is comparable in magnitude to that of heat is unaffected.

McGeehan and Maslowski (2011) suggested the important role of eddyinduced lateral freshwater flux from the western shelf of the Labrador Sea in restratifying the homogenized water columns. They did not make a quantitative comparison of the contribution of low salinity water from the western and eastern shelves (WGC and LC) on the restratification or buoyancy injection into the central Labrador Sea because of the poor reproduction of the low salinity water along the western coast of Greenland. The eddy-induced transport of freshwater from the western shelf (LC) is much smaller than that from the eastern shelf (WGC) in our model. Furthermore, hydrographic and mooring data demonstrate that the source of surface freshwater in the central Labrador Sea is the WGC (Schmidt and Send, 2007).

The freshwater in the WGC is mainly originated from the Arctic Ocean and propagated by the East Greenland Current (Aagaard and Carmack, 1989; Kwok et al., 2004). Kwok and Rothrock (1999) concluded that the interannual and decadal variability of the sea ice export through the Fram Strait has high correlation with the NAO or AO indices. This variability propagates to the WGC by the East Greenland Current through the Denmark Strait and around Cape Farewell. Supply of low density water to the Labrador Sea should have an associated interannual to decadal variability, and it influences the climate through open-ocean deep convection and the Atlantic thermohaline circulation. The relation between the interannual vari- 
ability of freshwater transport to the Labrador Sea and climate variability is worth investigating.

The Greenland Sea is also widely recognized as a region of open-ocean convection and formation of deep water. Since the Greenland Sea has similarities to the Labrador Sea with regard to the inflow of low density boundary currents originating in the Arctic Ocean and the North Atlantic Current, eddy-induced buoyancy transport from the boundary currents to the interior may also be important there. Previous observational and modeling studies suggested that deep convection events in the Labrador and Greenland Seas are anti-correlated (Dickson et al., 1996; Oka et al., 2006). Oka et al. (2006) concluded that the freshwater transport through the Denmark Strait controls the variability of deep convection in the Labrador and Greenland Seas. As the horizontal grid in their model is too coarse to resolve eddies, which contribute to the transport of heat and freshwater between the boundary currents and the Labrador Sea interior, it is worth reexamining this issue from the viewpoint of the role of boundary current eddies by incorporating an eddy-resolving ocean model.

\section{Acknowledgements}

This work is supported by the JST CREST and MEXT GRENE Arctic Climate Change Research Project. Numerical calculations were performed on SR16000 at Information Technology Center, University of Tokyo. Almost all figures are drawn by using the Grid Analysis and Display System (GrADS) developed by M. Doty and M. Fiorino. 


\section{References}

Aagaard, K., Carmack, E., 1989. The role of sea ice and other fresh water in the Arctic circulation. J. Geophys. Res. 94, 14485-14489.

van Aken, H.M., Femke de Jong, M., Yashayaev, I., 2011. Decadal and multi-decadal variability of Labrador Sea Water in the north-western North Atlantic Ocean derived from tracer distributions: Heat budget, ventilation, and advection. Deep Sea Res. I 58, 505-523.

Antonov, J.I., Seidov, D., Boyer, T.P., Locarnini, R.A., Mishonov, A.V., Garcia, H.E., Baranova, O.K., Zweng, M.M., Johnson, D.R., 2010. World Ocean Atlas 2009, Volume 2: Salinity. S. Levitus, Ed. NOAA Atlas NESDIS 69, U.S. Government Printing Office, Washington, D.C., 184 pp.

Avsic, T., Karstensen, J., Send, U., Fischer, J., 2006. Interannual variability of newly formed Labrador Sea Water from 1994 to 2005. Geophys. Res. Lett. 33, L21S02.

Bracco, A., Pedlosky, J., 2003. Vortex generation by topography in locally unstable baroclinic flows. J. Phys. Oceanogr. 33, 207-219.

Bracco, A., Pedlosky, J., Pickart, R., 2008. Eddy formation near the west coast of Greenland. J. Phys. Oceanogr. 38, 1992-2002.

Brandt, P., Schott, F., Funk, A., Martins, C., 2004. Seasonal to interannual variability of the eddy field in the Labrador Sea from satellite altimetry. J. Geophys. Res. 109, C02028. 
Bryden, H.L., Imawaki, S., 2001. Ocean Heat Transport in Ocean circulation and climate. Academic Press. chapter 6.1. pp. 455-477.

Chanut, J., Barnier, B., Large, W., Debreu, L., Penduff, T., Molines, J.M., Mathiot, P., 2008. Mesoscale eddies in the Labrador Sea and their contribution to convection and restratification. J. Phys. Oceanogr. 38, 1617-1643. doi:10.1175/2008JPO3485.1.

Clarke, R.A., Gascard, J.C., 1983. The formation of Labrador Sea water. Part I: Large-scale processes. J. Phys. Oceanogr. 13, 1764-1778.

Cuny, J., Rhines, P.B., Niiler, P.P., Bacon, S., 2002. Labrador Sea boundary currents and the fate of the Irminger Sea Water. J. Phys. Oceanogr. 32, $627-647$.

Dickson, R., Lazier, J., Meincke, J., Rhines, P., Swift, J., 1996. Long-term coordinated changes in the convective activity of the North Atlantic. Prog. Oceanogr. 38, 241-295.

Eden, C., Boning, C., 2002. Sources of eddy kinetic energy in the Labrador Sea. J. Phys. Oceanogr. 32, 3346-3363.

England, M.H., 1993. Representing the global-scale water masses in ocean general circulation models. J. Phys. Oceanogr. 23, 1523-1552.

Fischer, J., Visbeck, M., Zantopp, R., Nunes, N., 2010. Interannual to decadal variability of outflow from the Labrador Sea. Geophys. Res. Lett. 37. 
Fox-Kemper, B., Ferrari, R., 2008. Parameterization of mixed layer eddies. Part II: Prognosis and impact. J. Phys. Oceanogr. 38, 1166-1179.

Fox-Kemper, B., Ferrari, R., Hallberg, R., 2008. Parameterization of mixed layer eddies. Part I: Theory and diagnosis. J. Phys. Oceanogr. 38, 11451165.

Fratantoni, P.S., Pickart, R.S., 2007. The western North Atlantic shelfbreak current system in summer. J. Phys. Oceanogr. 37, 2509-2533.

Gelderloos, R., Katsman, C., Drijfhout, S., 2011. Assessing the roles of three eddy types in restratifying the Labrador Sea after deep convection. J. Phys. Oceanogr. 41, 2102-2119.

Gelderloos, R., Straneo, F., Katsman, C.A., 2012. Mechanisms behind the temporary shutdown of deep convection in the Labrador Sea: Lessons from the Great Salinity Anomaly years 1968-71. J. Clim. 25, 6743-6755.

Griffies, S.M., Hallberg, R.W., 2000. Biharmonic friction with a Smagorinsky-like viscosity for use in large-scale eddy-permitting ocean models. Monthly Weather Rev. 128, 2935-2946.

Hasumi, H., 2006. CCSR Ocean Component Model (COCO) Version 4.0. volume 25. Center for Climate System Research, University of Tokyo.

Hatun, H., Eriksen, C.C., Rhines, P.B., 2007. Buoyant eddies entering the Labrador Sea observed with gliders and altimetry. J. Phys. Oceanogr. 37, $2838-2854$. 
Jones, H., Marshall, J., 1997. Restratification after deep convection. J. Phys. Oceanogr. 27, 2276-2287.

Katsman, C.A., Spall, M.A., Pickart, R.S., 2004. Boundary current eddies and their role in the restratification of the Labrador Sea. J. Phys. Oceanogr. 34, 1967-1983.

Khatiwala, S., Schlosser, P., Visbeck, M., 2002. Rates and mechanisms of water mass transformation in the Labrador Sea as inferred from tracer observations. J. Phys. Oceanogr. 32, 666-686.

Komuro, Y., Hasumi, H., 2005. Intensification of the Atlantic deep circulation by the Canadian Archipelago throughflow. J. Phys. Oceanogr. 35, 775-789.

Kulan, N., Myers, P.G., 2009. Comparing two climatologies of the Labrador Sea: Geopotential and isopycnal. Atmosphere-ocean 47, 19-39.

Kwok, R., Cunningham, G., Pang, S., 2004. Fram Strait sea ice outflow. J. Geophys. Res. 109, c09009-c01029.

Kwok, R., Rothrock, D., 1999. Variability of Fram Strait ice flux and North Atlantic oscillation. J. Geophys. Res. 104, 5177-5189.

Lavender, K.L., Davis, R.E., Owens, W.B., 2000. Mid-depth recirculation observed in the interior Labrador and Irminger Seas by direct velocity measurements. Nature 407, 66-69.

Lavender, K.L., Davis, R.E., Owens, W.B., 2002. Observations of openocean deep convection in the Labrador Sea from subsurface floats. J. Phys. Oceanogr. 32, 511-526. 
Lazier, J., 1980. Oceanographic conditions at ocean weather ship Bravo, 1964-1974. Atmosphere-Ocean 18, 227-238.

Lazier, J., Hendry, R., Clarke, A., Yashayaev, I., Rhines, P., 2002. Convection and restratification in the Labrador Sea, 1990-2000. Deep Sea Res. I 49, $1819-1835$.

Lilly, J.M., Rhines, P.B., 2002. Coherent eddies in the Labrador Sea observed from a mooring. J. Phys. Oceanogr. 32, 585-598.

Lilly, J.M., Rhines, P.B., Schott, F., Lavender, K., Lazier, J., Send, U., D'Asaro, E., 2003. Observations of the Labrador Sea eddy field. Prog. Oceanogr. 59, 75-176.

Lilly, J.M., Rhines, P.B., Visbeck, M., Davis, R., Lazier, J.R.N., Schott, F., Farmer, D., 1999. Observing deep convection in the Labrador Sea during winter 1994/95. J. Phys. Oceanogr. 29, 2065-2098.

Locarnini, R.A., Mishonov, A.V., Antonov, J.I., Boyer, T.P., Garcia, H.E., Baranova, O.K., Zweng, M.M., Johnson, D.R., 2010. World Ocean Atlas 2009, Volume 1: Temperature. S. Levitus, Ed. NOAA Atlas NESDIS 68, U.S. Government Printing Office, Washington, D.C., 184 pp.

Luo, H., Bracco, A., Di Lorenzo, E., 2011. The interannual variability of the surface eddy kinetic energy in the Labrador Sea. Prog. Oceanogr. 91, $295-311$.

Marshall, J., Schott, F., 1999. Open-ocean convection: Observations, theory, and models. Rev. Geophys. 37, 1-64. 
McGeehan, T., Maslowski, W., 2011. Impact of shelf-basin freshwater transport on deep convection in the western Labrador Sea. J. Phys. Oceanogr. 41. doi:10.1175/JPO-D-11-01.1.

Myers, P.G., Deacu, D., 2004. Labrador sea freshwater content in a model with a partial cell topographic representation. Ocean Modelling 6, 359377.

Myers, P.G., Donnelly, C., 2008. Water mass transformation and formation in the Labrador Sea. J. Clim. 21, 1622-1638.

National Geophysical Data Center, National Oceanic and Atmospheric Administration, . ETOPO2v2 Global Gridded 2-minute Database. http://www.ngdc.noaa.gov/mgg/global/etopo2.html.

Noh, Y., Kim, H.J., 1999. Simulations of temperature and turbulence structure of the oceanic boundary layer with the improved near-surface process. J. Geophys. Res. 104, 15621-15634.

Oka, A., Hasumi, H., Okada, N., Sakamoto, T.T., Suzuki, T., 2006. Deep convection seesaw controlled by freshwater transport through the Denmark Strait. Ocean Modelling 15, 157-176. doi:10.1016/j.ocemod.2006.08.004.

Pickart, R.S., Torres, D.J., Clarke, R.A., 2002. Hydrography of the Labrador Sea during active convection. J. Phys. Oceanogr. 32, 428-457.

Prater, M.D., 2002. Eddies in the Labrador Sea as observed by profiling RAFOS floats and remote sensing. J. Phys. Oceanogr. 32, 411-427. 
Prather, M.J., 1986. Numerical advection by conservation of second-order moments. J. Geophys. Res. 91, 6671-6681.

Rattan, S., Myers, P.G., Treguier, A.M., Theetten, S., Biastoch, A., Böning, C., 2010. Towards an understanding of Labrador Sea salinity drift in eddypermitting simulations. Ocean Modelling 35, 77-88.

Roske, F., 2005. Global oceanic heat and fresh water forcing datasets based on ERA-40 and ERA-15. Report on Earth System Science 13. Max-PlanckInst. fur Meteor., Hamburg.

Rykova, T., Straneo, F., Lilly, J.M., Yashayaev, I., 2009. Irminger Current Anticyclones in the Labrador Sea observed in the hydrographic record, 1990-2004. J. Mar. Res. 67, 361-384.

Schmidt, S., Send, U., 2007. Origin and composition of seasonal Labrador Sea freshwater. J. Phys. Oceanogr. 37, 1445-1454.

Straneo, F., 2006. Heat and freshwater transport through the central Labrador Sea. J. Phys. Oceanogr. 36, 606-628.

Tréguier, A.M., Theetten, S., Chassignet, E.P., Penduff, T., Smith, R., Talley, L., Beismann, J.O., Böning, C., 2005. The North Atlantic subpolar gyre in four high-resolution models. J. Phys. Oceanogr. 35, 757-774.

Weaver, A.J., Bitz, C.M., Fanning, A.F., Holland, M.M., 1999. Thermohaline circulation: High-latitude phenomena and the difference between the Pacific and Atlantic. Annual Rev. Earth and Planetary Sciences 27, $231-285$. 
776 Yashayaev, I., 2007. Hydrographic changes in the Labrador Sea, 1960-2005. 777 Prog. Oceanogr. 73, 242-276. 